LM-00K073

October 4, 2000

\title{
Stress Corrosion Crack Growth Rate Testing and Analytical Electron Microscopy of Alloy 600 as a Function of Pourbaix Space and Microstructure
}

N. Lewis, S.A. Attanasio, D.S. Morton, G.A. Young

This report was prepared as an account of work sponsored by the United States Government. Neither the United States, nor the United States Department of Energy, nor any of their employees, nor any of their contractors, subcontractors, or their employees, makes any warranty, express or implied, or assumes any legal liability or responsibility for the accuracy, completeness or usefulness of any information, apparatus, product or process disclosed, or represents that its use would not infringe privately owned rights. 


\title{
STRESS CORROSION CRACK GROWTH RATE TESTING AND ANALYTICAL ELECTRON MICROSCOPY OF ALLOY 600 AS A FUNCTION OF POURBAIX SPACE AND MICROSTRUCTURE
}

\author{
Nathan Lewis, Steven A. Attanasio, David S. Morton, and George A. Young \\ Lockheed Martin \\ P.O. Box 1072 \\ Schenectady, NY 12301
}

\begin{abstract}
Stress corrosion crack (SCC) growth rate tests and analytical electron microscopy (AEM) studies were performed over a broad range of environments and heat treatments of Alloy 600 . This effort was conducted to correlate bulk environmental conditions such as $\mathrm{pH}$ and electrochemical potential $(\mathrm{EcP})$ with the morphology of the SCC crack. Development of a 'library' of AEM morphologies formed by SCC in different environments is an important step in identifying the conditions that lead to SCC in components. Additionally, AEM examination of stress corrosion cracks formed in different environments and microstructures lends insight into the mechanism(s) of stress corrosion cracking. Testing was conducted on compact tension specimens in three environments: a mildly acidic oxidizing environment containing sulfate ions, a caustic environment containing $10 \% \mathrm{NaOH}$, and hydrogenated near-neutral buffered water. Additionally, stress corrosion cracking testing of a smooth specimen was conducted in hydrogenated steam. The following heat treatments of Alloy 600 were examined: mill annealed at $980^{\circ} \mathrm{C}$ (near-neutral water), mill annealed at $1010^{\circ} \mathrm{C}$ (steam), sensitized (acid and caustic), and mill annealed thealed to homogenize the grain boundary $\mathrm{Cr}$ concentration (caustic)

Crack growth rate (CGR) testing showed that sensitized Alloy 600 tested in the mildly acidic, oxidizing environment containing sulfate ions produced the fastest cracking $(\sim 8.8 \mu \mathrm{m} / \mathrm{hr}$ at $260^{\circ} \mathrm{C}$ ), and AEM examination revealed evidence of sulfur segregation to the crack tip. The caustic environment produced slower cracking $\left(\sim 0.4 \mu \mathrm{m} / \mathrm{hr}\right.$ at $\left.307^{\circ} \mathrm{C}\right)$ in the mill annealed + healed heat treatment but no observed cracking in the sensitized condition. In the caustic environment, fully oxidized carbides were present in the crack wake but not ahead of the crack tip. In near-neutral buffered water at $338^{\circ} \mathrm{C}$, the CGR was a function of dissolved hydrogen in the water and exhibited a maximum $(0.17 \mu \mathrm{m} / \mathrm{hr})$ near the transition between $\mathrm{Ni}$ and $\mathrm{NiO}$ stability. The cracks in near-neutral hydrogenated water exhibited $\mathrm{Cr}$-rich spinels and NiO-type oxides but no significant oxidation of grain boundary carbides. No clear effect of dissolved hydrogen on the crack wake morphology was apparent. In hydrogenated steam testing of a smooth specimen (CGR estimated as $\sim 0.7 \mu \mathrm{m} / \mathrm{hr}$ at $399^{\circ} \mathrm{C}$ ), metallic nickel nodules were evident in both the crack wake and on the specimen surface. Oxide particles having a similar size and shape to the microstructural carbides were found in the crack wake, suggesting that these particles are carbides that were oxidized by contact with the steam. The present results show that different environments often produce unique crack tip morphologies that can be identified via AEM.
\end{abstract}




\section{Introduction}

Stress corrosion cracking (SCC) of Alloy 600 occurs under a variety of environmental conditions at elevated temperatures (e.g., 260 to $399^{\circ} \mathrm{C}$ ). An excellent review of these SCCsusceptible environments has been provided by Staehle [1]. As part of this review, Staehle has organized Alloy $600 \mathrm{SCC}$ in the context of the Pourbaix diagram for nickel, and has identified eight zones of SCC susceptibility, as shown in Figure 1. The present paper reports data from SCC tests conducted within three of these eight zones: (i) mild acidic-oxidizing, (ii) alkalineslightly oxidizing and reducing, and (iii) broad pH-reducing (also referred to as low potential stress corrosion cracking, LPSCC). Although some comparison will be made in this paper as to the SCC propensity between these zones, the primary focus of this effort is to contrast Analytical Electron Microscopy (AEM) morphologies between the zones. Breummer et al. [2] have pointed out the importance of characterizing the AEM morphologies of crack growth rate specimens from tests with controlled environmental conditions. Development of a 'library' of AEM morphologies formed by SCC in different environments is important for interpreting the results of AEM studies performed on cracks in components exposed to time-varying environments, such as the steam generator tubing evaluation performed in [2]. A comparison between the AEM morphology of a cracked component and the 'library' of AEM morphologies from controlled environmental conditions may assist in determining the SCC-inducing environment(s).

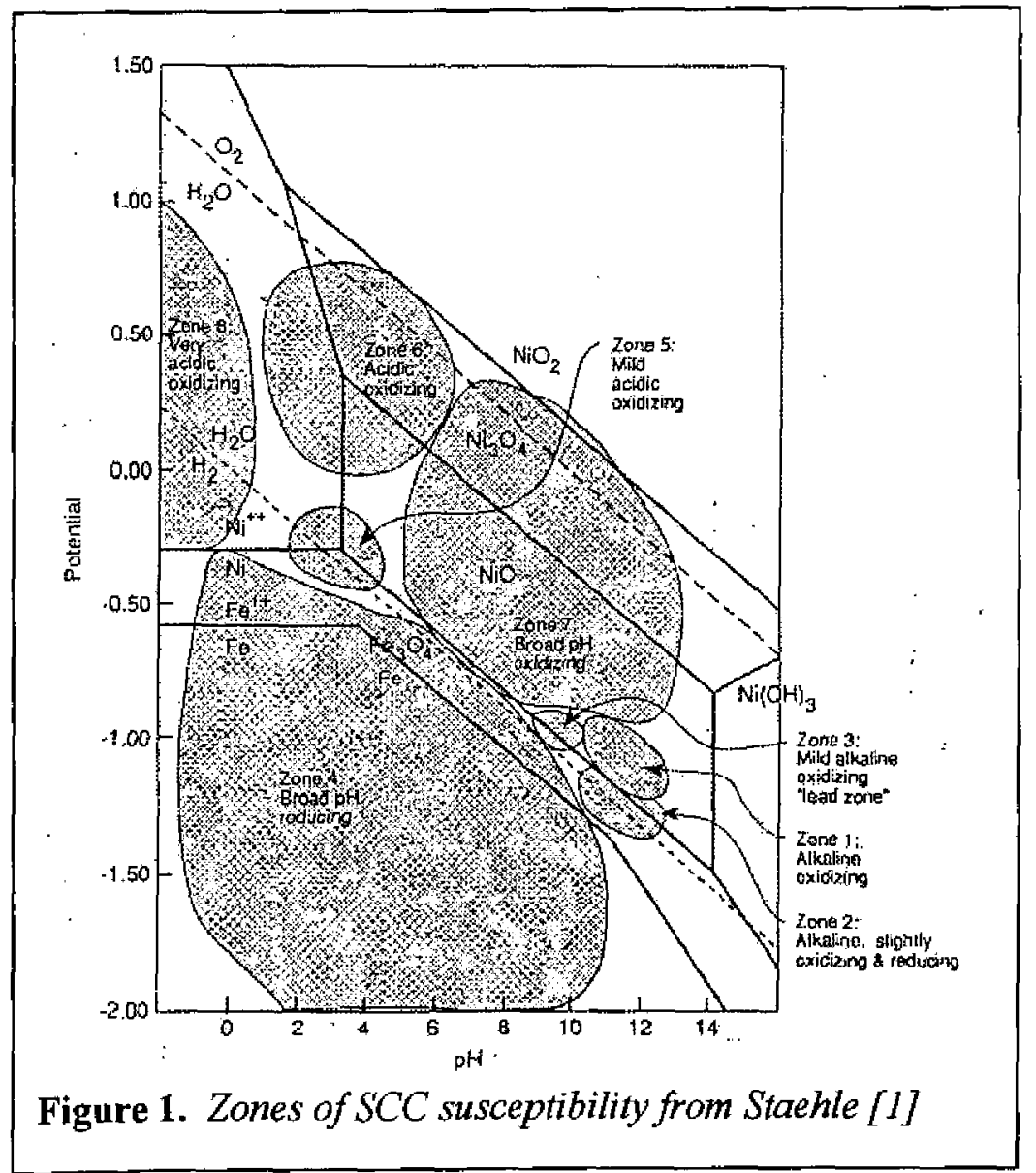

\section{Experimental}

\section{$\underline{\text { Materials }}$}

The compositions of the Alloy 600 (heats NX5853G11 and E8426) employed in this study are provided in Table $I$. Heat NX5853G11 has been used in prior stress corrosion crack growth rate (SCCGR), $\mathrm{AEM}$, and SCC modeling studies [3-5]. Note that heat E8426 was only used for the hydrogenated steam test. Four heat treatments were utilized, and are summarized in Table II. These heat treatments will be referred to as " $\mathrm{MA}^{980 "}$ or " $\mathrm{MA}$ "1010" for mill annealed heat treatments, "healed" for the mill annealed $+980^{\circ} \mathrm{C}$ for 7 days heat treatment, and "sensitized" for the healed $+607^{\circ} \mathrm{C}$ for 7.5 hour heat treatment.

Table I Composition of Alloy 600 Heats NX5853G11 and E8426 (wt. \%)

\begin{tabular}{ccccccccccccc}
\hline Heat & Ni & Cr & Fe & C & P & Mn & Si & Cu & Al & Ti & B & S \\
\hline NX5853GI1 & 75.40 & 15.54 & 7.76 & 0.07 & 0.007 & 0.25 & 0.29 & 0.11 & 0.17 & 0.35 & 0.003 & $<0.001$ \\
\hline E8426 & 76.34 & 15.42 & 6.88 & 0.05 & 0.012 & 0.24 & 0.53 & 0.01 & 0.23 & 0.24 & 0.005 & 0.006 \\
\hline
\end{tabular}


Table II Heat Treatments of Alloy 600

\begin{tabular}{|c|c|c|c|c|c|}
\hline Designation & Heat Treatment & Heat & Microstructure & $\begin{array}{c}\text { Avg. grain } \\
\text { diameter } \\
(\mu \mathrm{m})\end{array}$ & $\begin{array}{c}\sigma_{\mathrm{ya}} \\
(\mathbf{M P a})\end{array}$ \\
\hline $\mathrm{MA}^{980}$ & $\begin{array}{c}\text { As-received } \\
\text { Mill annealed (MA) } \\
\text { at } 980^{\circ} \mathrm{C}\end{array}$ & NX5853G11 & $\begin{array}{c}\sim 0.2 \mu \mathrm{m} \text { carbides }\left(\mathrm{M}_{7} \mathrm{C}_{3}\right) \\
\sim 200 \mathrm{~nm} \text { Cr depleted zone } \\
(\mathrm{Cr} \sim 10-13 \mathrm{wt} \%)\end{array}$ & 25 & 314 \\
\hline Healed & $\begin{array}{c}\mathrm{MA}+980^{\circ} \mathrm{C} \text { for } 7 \\
\text { days - water quench }\end{array}$ & NX5853G11 & $\begin{array}{c}\sim 0.5 \mu \mathrm{m} \text { carbides }\left(\mathrm{M}_{7} \mathrm{C}_{3}\right) \\
\text { No } \mathrm{Cr} \text { depletion near boundaries }\end{array}$ & 25 & 262 \\
\hline Sensitized & $\begin{array}{c}\mathrm{MA}+980^{\circ} \mathrm{C} \text { for } 7 \\
\text { days - water quench } \\
+607^{\circ} \mathrm{C} \text { for } 7.5 \\
\text { hours (air cool) }\end{array}$ & NX5853G1I & $\begin{array}{c}\sim 0.5 \mu \mathrm{m} \text { carbides }\left(\mathrm{M}_{7} \mathrm{C}_{3}\right) \\
+\sim 0.05 \mu \mathrm{m} \mathrm{M}_{23} \mathrm{C}_{6} \text { carbides } \\
\sim 150 \mathrm{~nm} \mathrm{Cr} \text { depletion zone } \\
(\mathrm{Cr} \sim 7-12 \text { wt } \%)\end{array}$ & 25 & N/A \\
\hline $\mathrm{MA}^{1010}$ & $\begin{array}{l}1010^{\circ} \mathrm{C} \text { for } 1 \text { hour } \\
\text { with water quench }\end{array}$ & E8426 & $\begin{array}{c}\sim 0.5 \mu \mathrm{m} \text { carbides }\left(\mathrm{M}_{7} \mathrm{C}_{3}\right) \\
\text { low carbide coverage }\end{array}$ & 82 & 262 \\
\hline
\end{tabular}

\section{Crack Growth Rate Testing}

SCCGR tests were conducted in three Pourbaix diagram (EcP-pH) regimes of SCC susceptibility: (i) mildly acidic $\mathrm{pH}(\sim 5.1)$ with an oxidizing $\mathrm{EcP}(\sim+140 \mathrm{mV}$ versus the Standard Hydrogen Electrode (SHE)) containing sulfate ions, (ii) alkaline $\mathrm{pH}^{1}(\sim 10.0)$ with a slightly reducing EcP $\left(\sim-960 \mathrm{mV}_{\mathrm{SHE}}\right)$, and (iii) near-neutral $\mathrm{pH}(\sim 6.7)$ at a range of relatively reducing EcPs $\left(\sim-670 \text { to }-780 \mathrm{mV}_{\mathrm{SHE}}\right)^{2}$. Note that condition (iii) is analogous to the LPSCC regime described by Staehle. In the near-neutral $\mathrm{pH}$ environment, nine separate tests were performed, each at a unique dissolved hydrogen concentration between 1 and $120 \mathrm{cc} \mathrm{H}_{2}$ (STP) $/ \mathrm{kg} \mathrm{H}_{2} \mathrm{O}$ (i.e., 0.6 to $\left.68.7 \mathrm{kPa}\right)^{3}$. The experimental details of the testing at different hydrogen levels have been given previously [6].

A summary of the environments and heat treatments used in this study is given in Table III. It is noted that all EcPs were produced by controlling dissolved gas concentration.

Table III Summary of Test Conditions Used in this Study

\begin{tabular}{|c|c|c|c|c|c|c|}
\hline $\begin{array}{l}\text { Environmental } \\
\text { Condition }\end{array}$ & $\begin{array}{c}\mathbf{T} \\
\left({ }^{\circ} \mathrm{C}\right)\end{array}$ & $\begin{array}{c}\text { Heat } \\
\text { Treatment }\end{array}$ & $\mathbf{p} \mathbf{H}^{(\mathbf{1})}$ & $\begin{array}{c}\mathbf{E c P}^{(2)} \\
\left(\mathbf{m} V_{\text {SHE }}\right)\end{array}$ & $\begin{array}{l}\text { Dissolved } \\
\text { Gas }\end{array}$ & CGR $(\mu \mathrm{m} / \mathbf{h r})$ \\
\hline $\begin{array}{c}\text { Mildly acidic } \\
\text { oxidizing with } \mathrm{SO}_{4}{ }^{2-}\end{array}$ & 260 & Sensitized & 5.1 & +140 & $8 \mathrm{ppm} \mathrm{O}_{2}$ & 8.8 \\
\hline \multirow{2}{*}{ Caustic } & 307 & Healed & $\overline{10.0}$ & -960 & $\mathrm{~N}_{2}$-deaerated & $\geq 0.41$ \\
\hline & 307 & Sensitized & 10.0 & -960 & $\mathrm{~N}_{2}$-deaerated & No SCC observed \\
\hline Near-neutral & 338 & $\mathrm{MA}^{980}$ & 6.7 & $\begin{array}{l}-670 \text { to } \\
-780\end{array}$ & $\begin{array}{c}1 \text { to } 120 \\
\mathrm{scc} / \mathrm{kg} \mathrm{H}_{2}^{(3)}\end{array}$ & $\begin{array}{c}0.05 \text { to } 0.17\left(\mathrm{~K}=27.5 \mathrm{MPa} V_{\mathrm{m}}\right) \\
0.17 \text { to } 0.46(\mathrm{~K}=66 \mathrm{MPa} \mathrm{m})\end{array}$ \\
\hline Hydrogenated steam & 399 & $\mathrm{MA}^{1010}$ & 6.7 & -890 & $\begin{array}{l}83 \mathrm{kPa} \mathrm{H}_{2}+ \\
\text { steam }\end{array}$ & $\begin{array}{c}0.7 \\
\text { (approximate) }\end{array}$ \\
\hline
\end{tabular}

Notes: The $399^{\circ} \mathrm{C}$ steam $\mathrm{pH}$ was assumed to be $\sim 6.7$; the $\mathrm{pH}$ of the starting water in the steam test was identical to the buffered water used in the near-neutral tests - the actual pH in the steam phase is not known. The EcP for the steam test was calculated as a hydrogen electrode with the assumed $\mathrm{pH}$ and a hydrogen fugacity of $83 \mathrm{kPa}$

All SCCGR tests were conducted with air fatigue precracked compact tension (CT) specimens Testing in the healed and sensitized heat treatments (i.e., mildly acidic oxidizing and alkaline

\footnotetext{
${ }^{1}$ Reported $\mathrm{pH}$ values were estimated by MULTEQ for the $\mathrm{pH}$ at test temperature.

${ }^{2}$ The EcPs for conditions (i) and (iii) were measured using an $\mathrm{Fe} / \mathrm{Fe}_{3} \mathrm{O}_{4}$ reference electrode. The EcP for condition (ii) was estimated by assuming a hydrogen electrode with $0.1 \mathrm{cc} / \mathrm{kg}$ dissolved hydrogen.

${ }^{3} \mathrm{I}$ to $120 \mathrm{cc} \mathrm{H}_{2}$ (STP)/kg H${ }_{2} \mathrm{O}$ (i.e., scc/kg) corresponds to a hydrogen partial pressure range of 0.6 to $68.7 \mathrm{kPa}$, using a Henry's Law constant [7] of $0.57 \mathrm{kPa} /(\mathrm{scc} / \mathrm{kg})$.
} 
tests) was performed with $0.4 \mathrm{~T} \mathrm{CT}$ specimens at an initial stress intensity factor of 27.5 MPa $\sqrt{m}$. Testing in the $\mathrm{MA}^{980}$ heat treatment (i.e., near-neutral $\mathrm{pH}$ tests) was performed with $1 \mathrm{~T}$ CT specimens at initial stress intensity factors ${ }^{4}$ of either 27.5 or $66 \mathrm{MPa}$ /m. The alkaline test was conducted in a static autoclave with bolt loaded specimens. All other testing was conducted in high flow rate recirculating facilities [3] with a constant load applied by a servoelectric actuator. Gentle load cycling ( $R$ of $0.7,0.01 \mathrm{~Hz}$, sinusoidal waveform) was also utilized in the acidic, mildly oxidizing test.

\section{SCC Testing in $399^{\circ} \mathrm{C}$ Hydrogenated Steam}

Steam testing was conducted with a smooth specimen subjected to manufacturing-induced residual stress. Due to the uncertainty in the actual level of residual stress present, a quantitative value of the stress on the specimen is not available. The specimen was exposed to $399^{\circ} \mathrm{C}$ steam having a hydrogen partial pressure of $83 \mathrm{kPa}$ for 615 days.

AEM Examinations. The AEM specimen preparation process for the cross-sectional examination of cracks has been described previously [8], and has been used in several other investigations [4, 8-13]. As shown in Figure 2, sectioning is performed to obtain a piece of the test specimen containing the SCC crack. After sectioning, mechanical grinding is conducted, followed by dimpling and ion milling (with argon ions) to form an electron transparent foil. The surface oxide preparation was performed by grinding an oxide-covered specimen from the substrate side to reach a depth of 75 to $125 \mu \mathrm{m}$. The oxide is then covered with electroplater's stop-off lacquer and electropolishing is conducted to remove the remainder of the substrate. Once the oxide is perforated by the electropolishing, the stop-off lacquer is removed using acetone; the surface oxide is then examined by AEM and $x$-ray diffraction. The AEM examinations were performed using a Philips $\mathrm{CM} 300$ instrument with a $\mathrm{LaB}_{6}$ filament, operated at $300 \mathrm{keV}$.

\footnotetext{
${ }^{4}$ Linear elastic fracture mechanics is non-valid for a 1 T CT specimen at the load associated with a pseudo stress intensity factor of $66 \mathrm{MPa} \mathrm{V}_{\mathrm{m}}$ or for a $0.4 \mathrm{~T} \mathrm{CT}$ specimen at a pseudo stress intensity factor of $27.5 \mathrm{MPa} / \mathrm{m}$.
} 


\section{Results}

\section{Crack Growth Rate Testing}

The Alloy 600 crack growth rates observed in this study in each of the environments investigated are shown in Figure 3 and are summarized in Table III.

Mildly acidic, oxidizing. The mildly acidic, oxidizing environment exhibited the most rapid SCCGR $(8.8 \mu \mathrm{m} / \mathrm{hr})$. This rapid crack growth occurred for Alloy 600 in the sensitized heat treatment, with significant grain boundary $\mathrm{Cr}$ depletion. It is interesting that of all the environmental and heat treatment conditions tested in this study, the fastest SCCGR occurred at the lowest test temperature, even though Alloy $600 \mathrm{SCC}$ susceptibility at near-neutral $\mathrm{pH}$ and low potentials increases with temperature following an Arrhenius thermal activation energy of $36 \mathrm{kcal} / \mathrm{mol}$ [14]. This result underscores the fact that while temperature is an important driving force, SCC of Alloy 600 is also strongly affected by EcP and $\mathrm{pH}$ (as well as material condition), as implied by the Pourbaix diagram in Figure 1. Another interesting aspect of the mildly acidic oxidizing test was that under pure constant load, it was difficult to incubate cracking (i.e., to start measurable crack growth) and to maintain cracking once it started. Upon initial heatup to $260^{\circ} \mathrm{C}$, under constant load, crack monitoring via reversing direct current electrical potential drop (EPD) indicated rapid crack growth $(3 \mu \mathrm{m} / \mathrm{hr})$. However, this rapid SCCGR was sustained for only 15 hours and cracking did not re-start during 35 additional hours of constant load exposure. However, rapid crack growth at a slightly higher rate $(\sim 5 \mu \mathrm{m} / \mathrm{hr})$ was immediately re-started upon the application of a gentle cyclic load $(R$ of $0.7,0.01 \mathrm{~Hz}$, expected fatigue CGR component $^{5}$ of $\sim 0.2 \mu \mathrm{m} / \mathrm{hr}$ ). When the cyclic load was subsequently transitioned to constant load, this rapid SCCGR was sustained for several days until the load was removed.

Caustic. In the alkaline environment $\left(10 \% \mathrm{NaOH}, \mathrm{pH}\right.$ of $\sim 10.0$, EcP of $\left.\sim-960 \mathrm{mV}_{\mathrm{SHE}}\right)$, SCC did not occur for Alloy 600 in the sensitized heat treatment. However, the material which was heat treated to homogenize the grain boundary chromium level to bulk values (i.e., the healed heat treatment) readily cracked in this environment, at a crack growth rate ${ }^{6}$ of $\geq 0.41 \mu \mathrm{m} / \mathrm{hr}$.

Near-neutral hydrogenated. Details of the CGR tests in the near-neutral buffered environment as a function of dissolved hydrogen concentration (i.e., conducted over a range of reducing EcPs) are provided in [6]. Consistent with other studies [15], these tests showed a maximum CGR with respect to dissolved hydrogen concentration (Figure 3). At $338^{\circ} \mathrm{C}$, this maximum CGR $(\sim 0.5$ $\mu \mathrm{m} / \mathrm{hr}$ at $66 \mathrm{MPa} \sqrt{\mathrm{m}}$ and $0.17 \mu \mathrm{m} / \mathrm{hr}$ at $27.5 \mathrm{MPa} / \mathrm{m}$; see inset of Figure 3) occurs at $\sim 30 \mathrm{scc} / \mathrm{kg}$ for $\mathrm{MA}^{980}$ Alloy 600 . This maximum in susceptibility coincides with the $\mathrm{Ni} / \mathrm{NiO}$ phase transition; thus, Reference [6] concluded that the dissolved hydrogen level SCCGR functionality is fundamentally quantifiable by the extent that the corrosion potential of the metal deviates from the corrosion potential of the $\mathrm{Ni} / \mathrm{NiO}$ phase transition.

SCC Testing in $399^{\circ} \mathrm{C}$ Hydrogenated Steam. A maximum crack depth of approximately $0.89 \mathrm{~cm}$ was measured via post-removal destructive evaluation. Cracking was first detected on the surface during an interim inspection at 43 days, and the total test time was 615 days. Assuming the time for crack growth to be 572 days (i.e., subtracting the crack incubation period), an approximate crack growth rate of $\sim 0.65 \mu \mathrm{m} / \mathrm{hr}$ was calculated.

\footnotetext{
${ }^{5}$ Fatigue CGRs were estimated from EPD measurements at $66^{\circ} \mathrm{C}$ on the same specimen.

${ }^{6}$ Since this bolt loaded specimen was not instrumented, the actual time to incubate crack growth was unknown. Thus, the CGR is reported as greater than or equal to and the value was calculated using zero incubation time.
} 


\section{AEM Examinations}

Cross-sectional AEM examinations were conducted on specimens from the four environments tested, predominantly focusing on the SCC crack and the bulk surface oxide. The results are summarized below.

Mildly Acidic, Oxidizing Condition. As shown in Figures 4 through 7, the crack was found to preferentially propagate intergranularly along the carbide-matrix interfaces. This finding is consistent with expectations, since the $\mathrm{Cr}$-depleted zone adjacent to the carbides should be the preferred crack path in a reduced $\mathrm{pH}$ environment ${ }^{7}$. The carbides were intact, with no significant carbide oxidation, as shown in Figures 5, 6, and 7. Evidence that the carbides have not been oxidized is given by the parallel markings in the carbide particles, which are planar faults commonly observed in $\mathrm{Cr}_{7} \mathrm{C}_{3}$. The presence of non-oxidized carbides is consistent with prior work under acid sulfate conditions [8]. The oxide in the crack typically exhibited a fine-grained structure which resulted in a 'speckled' appearance (Figures 5 and 6), but certain regions also exhibited an acicular structure as shown in Figures 6 and 8. Electron diffraction patterns from the oxide index to NiO-type and to an unidentified textured phase are shown in the inset of Figure 8 .

In this specimen, the oxide in the crack was relatively thick (e.g., Figure 8) compared to specimens tested in near neutral hydrogenated water or steam, for example. The oxide completely filled wide portions of the crack. The thick oxide is believed to be further evidence of appreciable corrosion within the crack. Sulfur was frequently found to be associated with the oxides within the crack, as shown by the energy dispersive spectroscopy (EDS) spectrum in Figure 9. However, sulfur was not detected in the oxides on the bulk surface as shown in Figure 10 (note that the electron diffraction pattem from this area indexes to $\mathrm{CrOOH}$, as shown in Figure 10). This observation is consistent with work by Andresen and Young [16], which showed that in an oxidizing environment, anions will concentrate in the crack due to a gradient in $\mathrm{EcP}^{8}$.

\footnotetext{
${ }^{7}$ In an oxidizing environment with anion contamination the $\mathrm{pH}$ in the crack is lower than the bulk $\mathrm{pH}$ [16]. This situation occurs because a gradient in EcP exists from the crack mouth (aerated) to the crack tip (deaerated).

${ }^{8}$ In an aerated environment, the crack tip has been shown to be deaerated [16]; the resulting EcP gradient along the crack concentrates anions at the tip. Anion concentration has been confirmed by crack tip microsampling [16].
} 
$10 \%$ Caustic Condition. Figure 11 shows a portion of the IG crack formed in this environment. This region of the crack propagated around a carbide and a triple point near the upper right of the photo. The darker portion on the left is $\mathrm{Cr}_{7} \mathrm{C}_{3}$, while the lighter portion on the right has been oxidized to form $\mathrm{Cr}_{2} \mathrm{O}_{3}$. The oxidized portion of the carbide is enriched in $\mathrm{Fe}$ and $\mathrm{Ni}$ relative to the non-oxidized portion of the carbide and shows trace levels of $\mathrm{Na}$. Figure 12 shows a somewhat similar observation for a different carbide. In this case, the fine-grained, 'speckled' region on the left is $\mathrm{Cr}$-rich oxide, while the lighter area with some evidence of parallel planar faults running right to left is $\mathrm{Cr}_{7} \mathrm{C}_{3}$ as seen in the electron diffraction pattern to the right of Figure 12a. Figure 12b shows the EDS signal from the oxidized portion of the carbide showing a high level of chromium, oxygen and increased Fe relative to a non-oxidized carbide. Note that there is no $\mathrm{Na}$ observed at this location. In this case, the oxidized portion of the carbide exhibits a spinel structure?, as shown by the diffraction pattern to the left of Figure 12a (note that the diffraction rings are quite diffuse, however). The oxide in the crack away from the carbides is shown in Figure 13. An array of $\mathrm{Cr}$-rich crystallites containing $\mathrm{Ni}, \mathrm{Fe}, \mathrm{Ti}$ and a small $\mathrm{Na}$ signal are seen. The electron diffraction pattern obtained from the region can be indexed to a spinel structure. However, the rings are quite diffuse for crystallites $50-100 \mathrm{~nm}$ in size.

Carbide oxidation is believed to be caused by contact with the water in the cracks. The extensive oxidation of carbides in the crack wake is generally consistent with the AEM work performed by Thomas and Bruemmer [17] on cracked Alloy 600 tubing taken from the Oconee \#3 plant. However, one apparent difference is that the present work in a caustic environment revealed no evidence of a layered, "onion-skin" morphology that was often present in the oxidized carbides in the Oconee cracks (Figure 14). This observation implies that perhaps the layered morphology observed by Thomas and Bruemmer [17] may result from repetitive carbide oxidation during multiple plant cycles, which are not present in the laboratory testing.

An additional finding in this test is that the specimen surface contains Ni nodules in the metallic (i.e., non-oxidized) form, as shown in Figure 15. All of the testing in this study was conducted in stainless steel autoclaves, with the exception of the caustic testing, which was conducted in a nickel autoclave. Given this difference in vessel materials, it is expected that the environment is saturated with respect to nickel ions in the caustic testing, but not in the other aqueous test environments. This fact helps explain the extensive presence of Ni-rich deposits on the surface of the caustic specimen, but does not explain why the $\mathrm{Ni}$ was present in the reduced (i.e., metallic) form. This result is unexpected since the test environment was nitrogen-deaerated, which should produce an $\mathrm{EcP}$ slightly electropositive to the $\mathrm{Ni} / \mathrm{NiO}$ phase transition. This result is not understood at present; however, it is possible that hydrogen buildup occurred during the test since the caustic testing was conducted in a static nickel autoclave. It is noted that the crack itself contained oxide, but did not contain the metallic nickel observed on the surface. The reason for different findings on the surface and within the crack is not understood at present.

\footnotetext{
${ }^{9}$ A spinel structure refers to an oxide with the general formula $\mathrm{Ni}_{1-x} \mathrm{Fe}_{x} \mathrm{Cr}_{2-y} \mathrm{Fe}_{y} \mathrm{O}_{4}$.
} 
Near-Neutral Hydrogenated Water. The appearance of the SCC crack tips and crack wakes in the near-neutral buffered water were very similar for samples tested with $35 \mathrm{scc} / \mathrm{kg} \mathrm{H} \mathrm{H}_{2}(0.23$ $\mu \mathrm{m} / \mathrm{hr})$ and $120 \mathrm{scc} / \mathrm{kg} \mathrm{H}_{2}(\sim 0.07 \mu \mathrm{m} / \mathrm{hr})$, even though the crack growth rates differed by a factor of $3 \mathrm{X}$. In each sample, multiple SCC cracks initiated from the fatigue precrack. In the near crack-tip region $(<1 \mu \mathrm{m}$ from the tip) the crack was relatively full of oxides, while the oxides were intermittent farther in the wake. It is unclear whether or not environmental exposure or sample preparation affected the distribution of the oxide in the crack wake.

The near-neutral hydrogenated water specimens exhibited sharp crack tips with crack tip radii 2-3 nm and good registry between matching halves of the fracture surface indicating that very little general corrosion had occurred (Figure 16). The crack path was truly intergranular with no evidence of cracking along slip planes or off the grain boundary and proceeded around $\mathrm{Cr}_{7} \mathrm{C}_{3}-$ type carbides. In the crack wake, a thin layer of oxide on the carbide was commonly observed, both on the surface adjacent to the crack and between the carbide and the substrate (Figure 17), consistent with prior AEM work $[2,4]$ in near-neutral hydrogenated water. As shown in Figure 17 , the oxide layer on the carbides exhibits a thickness up to $\sim 20 \mathrm{~nm}$. This thin oxide layer is $\mathrm{Cr}$-rich, but efforts to obtain a valid diffraction pattern from this phase have been unsuccessful to date. Note that the thin layer observed between the substrate and the carbide is often associated with small secondary cracks on the substrate side of the carbide. No oxidation of carbides ahead of the crack tips was apparent.

The crack tip and crack wake oxides consisted of $\mathrm{NiO}$-structure and spinel-structure oxides. It is important to note that, consistent with prior AEM findings [4], both iron and chromium were observed in the $\mathrm{NiO}$-structure oxide (i.e. $(\mathrm{Ni}, \mathrm{Cr}, \mathrm{Fe}) \mathrm{O}$ ). Both iron-rich spinels (e.g., $\left.\mathrm{NiFe}_{2} \mathrm{O}_{4}\right)$ and chromium-rich spinels (e.g., $\mathrm{NiCr}_{2} \mathrm{O}_{4}$ ) were observed, with the $\mathrm{Cr}$-rich spinel being the most common spinel form observed. The high resolution AEM image in Figure 18 shows a chromium-rich, spinel-structure oxide embedded in the NiO-structure oxide near the crack tip of the specimen tested in $120 \mathrm{scc} / \mathrm{kg}$ hydrogen.

No clear evidence of internal oxidation of the microstructure was apparent, either ahead of the crack tip or on small cracks emanating from the main crack. Additionally, no evidence of voids ahead of the crack tip was observed.

Although there were no discernible differences in the AEM morphology between the specimens tested at 35 and $120 \mathrm{scc} / \mathrm{kg}$, it is possible that morphology differences might result if a specimen tested at a much lower hydrogen concentration, well into the $\mathrm{Ni}$ oxide stability regime, were examined by AEM. Such specimens have not been examined by AEM methods to date. 
$399^{\circ} \mathrm{C}$ Hydrogenated Steam Condition. A noteworthy aspect of this specimen, as shown via scanning electron microscopy (SEM) photographs, is the presence of metallic Ni nodules on the specimen surface (Figure 19), and along most of the crack wake (Figure 20). The nodules were verified to consist essentially of $\mathrm{Ni}$ via EDS, and the phase identification was performed by micro-diffraction, as shown in Figure 21 . The Ni nodules have not been typically observed on specimens examined by AEM [4,8-13]. Their presence in this specimen may be due to the reducing nature of the environment (i.e., $\mathrm{P}_{\text {bydrogen }}$ of $83 \mathrm{kPa}$ ). Also, the precipitation kinetics may be affected by the steam and/or aqueous environment. The environment may be saturated with respect to nickel ions in this case (similar to the caustic case described above), since the nickel ions cannot diffuse away into the bulk water as they can in an aqueous test environment. Interestingly, as one moves along the crack wake in the direction of the crack tip, the Ni nodules are no longer present (Figure 22). The reason for the absence of the Ni nodules in the near crack tip region is not known. It is possible that the conditions are less reducing near the crack tip. It is also conceivable that this observation may be related to formation kinetics (i.e., the time available for precipitation is lower near the crack tip since this is the most recently created surface), or perhaps to the access of steam and/or condensed water to the crack tip region. Additionally, it is possible that capillary action affects the condensation of steam, which might affect the $\mathrm{Ni}$ nodule formation within the crack.

The Ni nodules are believed to form via a reprecipitation process, rather than via dealloying. Key supporting evidence is shown in Figure 21, in which twinning is evident within the metallic $\mathrm{Ni}$ nodules, with no clear orientation relationship to the base metal. In other words, the twins do not appear to have been formed in the base metal followed by dealloying of $\mathrm{Cr}$ and $\mathrm{Fe}$, but rather, the $\mathrm{Ni}$ appears to have reprecipitated on the surface, forming twin boundaries in the metallic nickel which are independent of the base metal orientation.

The bulk surface oxide (Figure 25) exhibits a spinel structure with faceted crystallites. The large crystals are $\mathrm{NiFe}_{2} \mathrm{O}_{4}$ and the smaller crystals are $\mathrm{Ni}_{\mathrm{x}} \mathrm{Fe}_{(1-\mathrm{x})} \mathrm{Cr}_{2} \mathrm{O}_{4}$ (with $\mathrm{Ni}$ metal precipitates also occasionally observed). These structures are similar to that observed for the bulk oxides in nearneutral hydrogenated water, though $\mathrm{Ni}$ metal was not found on the surface of those samples.

Another unusual aspect of this specimen is the presence of single crystal oxide particles found along the crack wake, as shown in Figure 23a. These single crystal oxide particles exhibit a spinel structure. It is believed that these particles represent oxidized carbides, but the evidence is not definitive. Key evidence supporting this view is that the general size and shape of the oxide particles is similar to the size and shape of the microstructural carbides (Figure 23b). However, as shown in Figure 24a, these particles contain appreciable $\mathrm{Fe}$ and $\mathrm{Ni}$ which is not present in the microstructural chromium carbides, as shown in Figure 24b (note that the EDS spectra for the $\mathrm{Ni}$ metal precipitate and the alloy matrix are included for comparison in Figures $24 \mathrm{c}$ and $24 \mathrm{~d}$, respectively).

It is not obvious how these oxide particles could have formed via carbide oxidation, given the significant level of iron and $\mathrm{Ni}$ present. However, partially and fully oxidized carbides found in the caustic environment that contain fine-grained polycrystalline chromium-rich oxides also show increased Fe compared to the non-oxidized carbide. Note that in the steam test, no partially oxidized carbides were observed, albeit for only a limited number of grain boundaries examined (the presence of partially oxidized carbides is believed to represent the most definitive way of determining whether a given oxide particle was initially a carbide). If the judgement that these oxide particles represent oxidized carbides is correct, then this observation is generally consistent with the presence of oxidized carbides in AEM specimens taken from the superheated region (i.e., the steam phase) of Oconee [17]. It is possible that in both cases (i.e., laboratory 
steam and the superheated region of Oconee), a steam environment may have promoted the oxidation of microstructural carbides in Alloy 600. However, there are some differences between the oxidized carbides in the steam test and in the Oconee cracks. For example, a layered, 'onion-skin' morphology was not observed in the oxidized carbides from the steam test. Also, the oxidized carbides in Oconee consisted of fine-grained $\mathrm{Cr}_{2} \mathrm{O}_{3}$, while the oxidized carbides in the steam test consisted of single crystal spinel oxides. Some of these differences may be related to the higher temperature of the steam test $\left(399^{\circ} \mathrm{C}\right)$, which may promote more rapid carbide oxidation kinetics. 


\section{Discussion}

\section{Summary of Findings}

A key objective of this study was to identify distinguishing characteristics, or 'signature' features in the AEM morphologies developed in different environments. Distinguishing characteristics and data related to both crack and surface oxides are summarized in Table IV for each environment-material condition tested.

Table IV Summary of Characteristic Findings for Each Environmental Condition

\begin{tabular}{|c|c|c|c|c|}
\hline $\begin{array}{c}\text { Test } \\
\text { Environment }\end{array}$ & $\begin{array}{c}\text { Heat } \\
\text { Treatment }\end{array}$ & $\begin{array}{l}\text { Distinguishing } \\
\text { Features }\end{array}$ & $\begin{array}{c}\text { Crack Oxide } \\
\text { Characteristics and } \\
\text { Composition }\end{array}$ & $\begin{array}{c}\text { Bulk Surface Oxide } \\
\text { Characteristics and } \\
\text { Composition }\end{array}$ \\
\hline $\begin{array}{l}\text { Acidic, } \\
\text { mildly } \\
\text { oxidizing } \\
\left(260^{\circ} \mathrm{C}\right)\end{array}$ & Sensitized & $\begin{array}{l}\text { - Carbides not } \\
\text { oxidized } \\
\text { - S associated } \\
\text { with crack } \\
\text { oxides but not } \\
\text { surface oxides }\end{array}$ & $\begin{array}{l}\text {-Oxide more voluminous } \\
\text { than for other conditions } \\
\text { - Sulfur associated with crack } \\
\text { oxide } \\
\text { - Comparatively higher \% } \mathrm{Ni} \\
\text { in oxide compared to caustic }\end{array}$ & $\begin{array}{l}\text { - Acicular } \mathrm{Cr} \text { and } \mathrm{Cr}+\mathrm{Ni} \text { rich } \\
\text { oxide } \\
\text { - XRD shows } \mathrm{CrOOH} \\
\text { (substituted) + } \mathrm{NiO} \\
\text { - Sulfur not associated with } \\
\text { surface oxide }\end{array}$ \\
\hline $\begin{array}{l}\text { Caustic } \\
\left(307^{\circ} \mathrm{C}\right)\end{array}$ & Healed & $\begin{array}{l}\text {-Fully and } \\
\text { partially } \\
\text { oxidized } \\
\text { carbides }\end{array}$ & $\begin{array}{l}\text { - Oxidized carbides are either } \\
\mathrm{Cr}_{2} \mathrm{O}_{3} \text { or spinel structure } \\
\text { - Oxide in crack Cr-rich } \\
\text { - Na sometimes observed } \\
\text { associated with crack oxide }\end{array}$ & $\begin{array}{l}\text { - Ni metal on surface (Ni metal } \\
\text { not seen in crack) }\end{array}$ \\
\hline $\begin{array}{l}\text { Near-neutral, } \\
\text { hydrogenated } \\
\quad\left(338^{\circ} \mathrm{C}\right)\end{array}$ & $\begin{array}{c}\text { Mill } \\
\text { annealed at } \\
980^{\circ} \mathrm{C} \\
\left(\mathrm{MA}^{980}\right)\end{array}$ & $\begin{array}{l}\text {-Carbides not } \\
\text { oxidized } \\
\text {-No clear effect } \\
\text { of dissolved } \mathrm{H}_{2} \\
\text { (between } 35 \text { and } \\
120 \mathrm{scc} / \mathrm{kg} \mathrm{H}_{2} \text { ) }\end{array}$ & $\begin{array}{l}\text { - Cr-rich spinel and Ni oxides } \\
\text { Oxide crystallites are nm } \\
\text { size, with occasional blocky } \\
50 \mathrm{~nm} \text { crystallites } \\
\text {-Cr-rich layer ( } 2-20 \mathrm{~nm}) \\
\text { between carbide/matrix along } \\
\text { crack wake }\end{array}$ & $\begin{array}{l}\text {-Cr-rich spinel inner layer } \\
\text { - } \mathrm{NiFe}_{2} \mathrm{O}_{4} \text { outer layer - } \\
\text { blocky, faceted crystallites } \\
\text { occasional } \mathrm{Cr}_{2} \mathrm{O}_{3}\end{array}$ \\
\hline $\begin{array}{l}\text { Hydrogenated } \\
\text { steam } \\
\left(399^{\circ} \mathrm{C}\right)\end{array}$ & $\begin{array}{c}\text { Mill } \\
\text { annealed at } \\
1010^{\circ} \mathrm{C} \\
\left(\mathrm{MA}^{1019}\right)\end{array}$ & $\begin{array}{l}\text { - Ni nodules on } \\
\text { surface and in } \\
\text { most of crack } \\
\text { - Single crystal } \\
\text { spinel particles } \\
\text { (likely oxidized } \\
\text { carbides) }\end{array}$ & $\begin{array}{l}\text { - Single crystal spinels that } \\
\text { appear to be oxidized } \\
\text { carbides } \\
\text { - Metallic Ni nodules except } \\
\text { near the crack tip } \\
\text {-Cr-rich oxides away from } \\
\text { carbides }\end{array}$ & $\begin{array}{l}\text {-Cr-rich spinel inner layer } \\
-\mathrm{NiFe}_{2} \mathrm{O}_{4} \text { outer layer - blocky, } \\
\text { faceted crystallites } \\
\text { - Metallic Ni nodules }\end{array}$ \\
\hline
\end{tabular}

Note: In all cases, the crack path was intergranular, and propagated around grain boundary carbides.

To identify distinguishing characteristics for different environmental conditions, the environmental parameters were divided into four categories (oxidizing and reducing potentials, high and low $\mathrm{pH}$ ). A discussion of each of these categories is provided below.

Oxidizing Potentials. The most apparent 'signature' of the mildly acidic, oxidizing test was the detection of sulfur associated with oxides in the crack, but not on the bulk surface. This determination is consistent with crack tip microsampling data [16], in which an aerated environment was shown to concentrate anionic species in the crack. Thus, if one detected an element associated with an anionic species (e.g., sulfate) within the crack but not on the bulk surface, this observation might indicate that the specimen was exposed to an oxidizing environment. Also, the textured phase present in the crack might represent a characteristic species since it has not been observed previously; however, its identification is not presently known 
Reducing Potentials. Metallic Ni nodules were present extensively in the hydrogenated steam test, which was the most reducing condition tested in this study (83 $\mathrm{kPa}$ hydrogen fugacity, resulting in a calculated $\mathrm{EcP}$ of $-890 \mathrm{mV}_{\mathrm{SHE}}$ ). This observation suggests that if one performed an AEM examination of a cracked specimen exposed to an unknown environment, the presence of metallic Ni may be an indication of exposure to a reducing environment. However, an ambiguity exists with respect to the fact that metallic $\mathrm{Ni}$ was also detected on the surface of the caustic exposed specimen, which was not believed to be exposed to a highly reducing environment (though, as described above, hydrogen buildup may have occurred in the static autoclave used to test the caustic specimen). In the caustic case, no evidence of Ni metal was observed within the crack.

High $\mathrm{pH}$. The oxidation of carbides to fine-grained $\mathrm{Cr}_{2} \mathrm{O}_{3}$ and spinel appears to be a consistent feature in specimens exposed to $10 \mathrm{wt} \%$ caustic ( $\mathrm{pH}$ calculated as 10.0). Note that evidence of oxidized carbides due to caustic exposure has been obtained in non-sensitized Alloy 600 (in this study) and in sensitized Alloy 600 [9]. Fully or partially oxidized carbides have not been found in environments such as hydrogenated near-neutral water, all-volatile treatment, phosphated boiler water, and acid sulfate [4, 8-13]. The presence of oxidized carbides may not be a unique characteristic of a caustic environment, however, given the strong possibility that the single crystal spinel oxides in the hydrogenated steam test may have formed by carbide oxidation.

Low $\mathrm{pH}$. The oxide within the crack was found to be fairly voluminous in the mildly acidic oxidizing specimen, which was expected to have a relatively low $\mathrm{pH}$ environment in the crack. Realize, however, that the relatively thick oxide was found for a sensitized heat treatment and the same amount of oxide production might not be found in a specimen that did not exhibit extensive $\mathrm{Cr}$ depletion. Additionally, the $\% \mathrm{Ni}$ in the crack oxides tended to be higher in the mildly acidic, oxidizing specimen than in the caustic specimen.

\section{Implications for Proposed SCC Mechanisms}

Internal Oxidation Mechanism. Scott [18] has used the AEM data of Thomas and Bruemmer [17] to argue that internal oxidation (TO) is the likely SCC mechanism in Oconee, and perhaps for other instances of Alloy $600 \mathrm{SCC}$. According to this mechanism, oxygen ingress along intergranular penetrations (IGPs) degrades the grain boundaries, leading to eventual cracking. A key piece of Scott's supporting evidence for the IO mechanism is the absence of impurity ions associated with the oxide film along IGP regions [18] which he asserts would be present if water had access to the oxidized region. Others, including Staehle [19] have argued against the IO mechanism, suggesting that the IGPs are tight cracks that formed oxide as a result of exposure to the aqueous environment within the crack. The present work indicates that species known to be present in the aqueous environment are sometimes found associated with the oxide films, and sometimes are not detected. As an example, for the mildly acidic oxidizing environment which contained sulfate anions, sulfur was often found associated with the oxides within the crack but was not found associated with the surface oxide. Therefore, even though it is known for certain that sulfur $\left(0.5 \mathrm{ppm} \mathrm{H}_{2} \mathrm{SO}_{4}\right.$ ) was present in the bulk water, one could not have discerned that fact by analyzing the surface oxide. Similarly, testing in caustic has revealed that sodium is sometimes detected in the oxide films, and sometimes is not detected. For example, prior work in $10 \%$ caustic [9] showed that sodium ions were not found associated with the crack oxide. However, in the caustic specimen examined in the present study, sodium was found associated with the oxide films in some locations, and absent in other locations. Thus, it is not clear that the presence or absence of species associated with the oxide film provides a consistent determination of whether the species was present in the environment. These observations suggest that an absence of water-borne chemical species associated with an oxide is not conclusive evidence that 
water did not contact the oxide. Therefore, the absence of chemical species associated with a particular grain boundary oxide does not appear to provide definitive evidence that the oxide in question formed by an IO process.

No direct evidence of IO was observed in this study. Evidence of oxidation on grain boundaries ahead of the crack tip were not observed, and carbide oxidation occurred only in the crack wake, never ahead of the crack tip. It was typical to find oxide-filled grain boundaries along the crack wake, though these are judged to represent tight secondary cracks that were formed by exposure to water rather than grain boundaries degraded by an IO process. The grain boundaries along the crack wake did not appear to contain metallic Ni 'sponge' as reported for the Oconee cracks [17]. Nickel sponge has been used by Scott to argue for the occurrence of preferential oxidation of $\mathrm{Cr}$ due to IO.

Film Rupture Oxidation Mechanism. The IGSCC crack growth of sensitized stainless steels in aerated high purity water has been effectively modeled using a film rupture oxidation (FRO) mechanism, also known as the slip-dissolution mechanism [20]. Ford and Andresen have also advanced the view that SCC of sensitized nickel-base alloys in aerated high purity water occurs by the FRO mechanism [21]. At near-neutral $\mathrm{pH}$ and low potential conditions (i.e., LPSCC), however, the mechanism of Alloy $600 \mathrm{SCC}$ has been the subject of debate for the last 25 years.

In the present work, it was noted that the AEM crack morphology of the specimen tested in the mildly acidic, oxidizing (i.e., aerated) environment was reasonably. consistent with the crack features observed in near-neutral buffered hydrogenated water (i.e., in the LPSCC regime). Cracks went around grain boundary carbides and the carbides were not appreciably oxidized. The extent of corrosion, as estimated from crack wake oxide thickness, was greater in the mildly acidic, oxidizing specimen compared with the LPSCC specimen. In the context of the FRO mechanism, the observed increased crack flank corrosion and higher CGR of the acidic, mildly oxidizing specimen is consistent with the higher metal solubility limits associated with the reduced $\mathrm{pH}$ crack tip environment of this specimen, and its depletion in grain boundary $\mathrm{Cr}$.

If one accepts the view that IGSCC of sensitized Alloy 600 in an acidic, mildly oxidizing environment occurs via the FRO mechanism [21], the general similarity between the crack morphologies of this specimen and the LPSCC specimens suggests that FRO may be a viable candidate mechanism for LPSCC. However, these microstructural similarities by no means prove that FRO is the operative LPSCC mechanism. Following this point, with regard to key material sensitivities (e.g., sensitization, grain boundary carbide coverage) it is interesting that the LPSCC and caustic exposure dependencies are often more similar than the LPSCC and aerated water exposure dependencies. For example, LPSCC and caustic Alloy 600 SCC are minimized by a high degree of grain boundary carbide coverage, while a high degree of sensitization enhances SCC in the mildly acidic, oxidizing environment. Additionally, there are several LPSCC characteristics unrelated to AEM studies that are somewhat difficult to explain via a FRO mechanism, such as the increased IGSCC observed under cathodic polarization [22].

Hydrogen-Assisted Cracking Mechanism. Evidence for a hydrogen embrittlement based mechanism of SCC of austenitic alloys exposed to primary water comes from experimental measurements of elevated hydrogen concentrations near stress corrosion cracks in Alloy X-750 [23], Alloy 600 [22, 24], and type 316 stainless steel [22]. Multiple researchers have shown that hydrogen concentrations near SCC fracture surfaces can contain approximately 10 to $100 \mathrm{wt}$. ppm hydrogen or on the order of 5 to 50 times the as-received hydrogen concentrations [22-24]. However, these experiments lack the spatial resolution to determine if hydrogen is the cause of crack advance or if the increased hydrogen concentrations are from cathodic reactions that 
support an anodic dissolution based mechanism. Post test examination of the oxide films in the crack wake and crack tip region via AEM can help elucidate the conditions under which hydrogen may contribute to or control the rate of stress corrosion crack advance.

Examination of crack tip oxide films is important, since corrosion reactions can produce high fugacities ( $>1 \mathrm{~atm}$ ) of hydrogen. The importance of hydrogen generated by electrochemical corrosion processes is highlighted by the work of Magnin et al. [24], who showed that for Alloy 600 in $360^{\circ} \mathrm{C}$ primary water, increased hydrogen levels are only observed in specimens that are undergoing stress corrosion cracking. Similarly, in Alloy X-750, Yonezawa et al. [23] did not observe maximum hydrogen levels at the largest amount of hydrogen dissolved in the water (40 cc $\mathrm{H}_{2}$ (STP) $/ \mathrm{kg} \mathrm{H}_{2} \mathrm{O}$ ). Instead, the maximum hydrogen concentration (43 wt. ppm) was observed near the $\mathrm{Ni} / \mathrm{NiO}$ transition of phase stability (20 to $30 \mathrm{cc} \mathrm{H}_{2}$ (STP)/kg H $\mathrm{H}_{2} \mathrm{O}$ at $360^{\circ} \mathrm{C}$ ) [23], which is consistent with the location of maximum SCC crack growth rates [6].

Given the importance of electrochemically produced hydrogen, the potential for a corrosion reaction to increase the hydrogen content in the metal and cause hydrogen damage can be estimated from the fugacity of hydrogen which the reaction produces at equilibrium. The fugacity of hydrogen and the temperature set the equilibrium concentration of hydrogen in a given material via Sievert's law. The theoretical fugacity of hydrogen $\left(f_{\mathrm{H}_{2}}\right)$ produced during corrosion is estimated from the Gibbs free energy change of the reaction $\left(\Delta G_{r x}^{\circ}\right)$ as shown in Equation 1 where $n_{H_{2}}$ are the number of moles of hydrogen gas produced, $R$ is the gas constant and $T$ is the temperature.

$$
f_{H_{1}}=\exp \left(\frac{-\Delta G_{r x}^{o}}{n_{H_{2}} \cdot R \cdot T}\right)
$$

Using the thermodynamic data compiled by Ziemniak [25] and taking the activity of water equal to 1 , the equilibrium fugacity of hydrogen produced by corrosion reactions of the major elements in Alloy 600 is summarized in Figure 26. Additionally, the equivalent fugacities for 10 and 100 $\mathrm{scc} / \mathrm{kg} \mathrm{H}_{2}$ are included in Figure 26 for comparison. The fugacities of hydrogen gas additions to the water were calculated from Henry's law using a coefficient of $0.35 \mathrm{kPa} /(\mathrm{scc} / \mathrm{kg} \mathrm{H})_{2}$ [7]. 


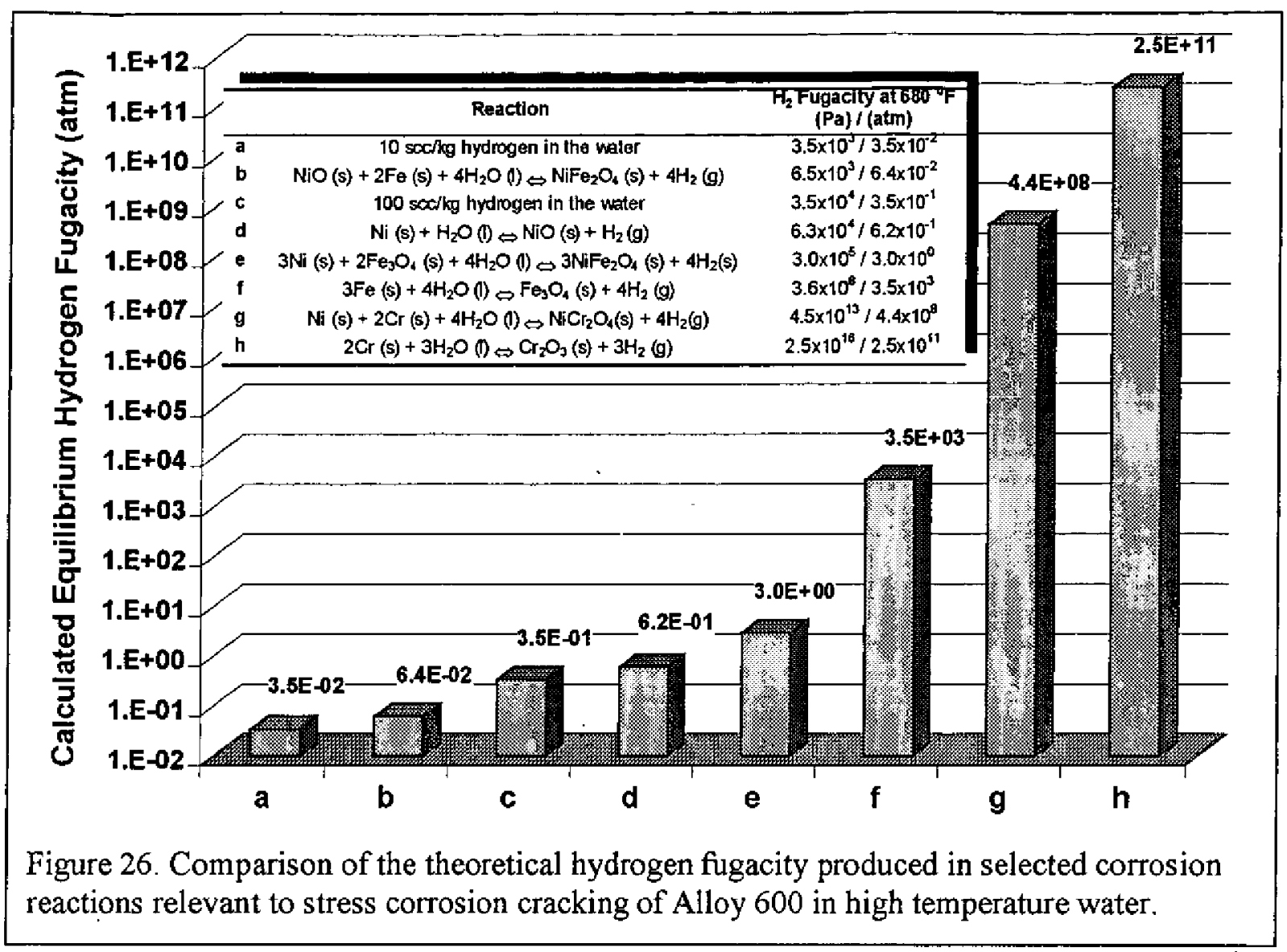

The ability of a given corrosion reaction to produce hydrogen concentrations of $\sim 10$ to $100 \mathrm{wt}$. ppm in Alloy 600 and Alloy X-750 can be assessed by considering stress enhanced solubility of hydrogen. Note that the effects of microstructural traps are ignored based on the weak $(\leq 10$ $\mathrm{kJ} / \mathrm{mol}$ ) interaction of stress and microstructural traps [26] and lack of significant hydrogen enrichment in regions that contain traps but are far away from regions of stress corrosion cracking [22-24, 27]. Using the expression of Wriedt and Oriani [28] and the solubility data of Symons [29], the stress enhanced solubility, $C_{H}^{\sigma}$, can be estimated from Equation 2 where $C_{0}$ is the Sievert's law constant, $f_{H_{2}}$ is the fugacity of hydrogen, $\Delta H_{\text {solution }}$ is the heat of solution, $\bar{V}_{H}$ is the partial molar volume of hydrogen in fcc metals $\left(1.75 \times 10^{-6} \mathrm{~m}^{3} / \mathrm{mol}\right)[30], \sigma_{y y}$ is the maximum tensile stress ahead of a blunted crack tip ( $3.8 \sigma_{Y S}$, where $\sigma_{Y S}$ represents the material yield strength) [31], $R$ is the gas constant and $T$ is the temperature. The parameters used to evaluate Equation 2 are given in Table $\mathrm{V}$.

$$
C_{H}^{\sigma}=C_{0} \cdot \sqrt{f_{H_{1}}} \cdot \exp \left(\frac{-\Delta H_{\text {soluation }}+\bar{V}_{H} \cdot \sigma_{y y}}{R \cdot T}\right)
$$


Table V Parameters used to calculate the effect of tensile stress on the solubility of hydrogen in Alloy 600 and Alloy X-750

\begin{tabular}{|c|c|c|c|c|c|}
\hline Alloy & $\begin{array}{c}\mathrm{C}_{0} \\
\left(\frac{w t \cdot p p m}{\sqrt{a t m}}\right)\end{array}$ & $\begin{array}{c}\Delta H_{\text {salution }} \\
\text { (J/mol) }\end{array}$ & $\begin{array}{c}\text { Temperature } \\
\left({ }^{\circ} \mathrm{C} /{ }^{\circ} \mathrm{F}\right)\end{array}$ & $\begin{array}{c}\text { Approximate } \sigma_{Y S} \\
\text { at } 360^{\circ} \mathrm{C} \\
(\mathrm{MPa} / \mathrm{ksi})\end{array}$ & $\frac{C_{H}^{\sigma}}{C_{H}^{\text {Noo }}}$ \\
\hline A600 & 10.9 & 8463 & $360 / 680$ & $255 / 37$ & 1.4 \\
\hline$X-750$ & 12.1 & 6990 & $360 / 680$ & $759 / 110$ & 2.6 \\
\hline
\end{tabular}

Analysis of the stress enhanced hydrogen solubility indicates that hydrogen fugacities between 1 and $100 \mathrm{~atm}$ are required to produce 10 to $100 \mathrm{wt}$. ppm hydrogen in Alloy X-750 and 10 to 1000 atm are required for Alloy 600 . Inspection of the theoretical hydrogen fugacities produced by corrosion (Figure 27) shows that the formation of $\mathrm{NiO}$ and $\mathrm{NiFe}_{2} \mathrm{O}_{4}$ produce relatively low hydrogen fugacities $(<1 \mathrm{~atm})$ while the formation of $\mathrm{Fe}_{3} \mathrm{O}_{4}, \mathrm{NiCr}_{2} \mathrm{O}_{4}$ or $\mathrm{Cr}_{2} \mathrm{O}_{3}$ produce significant hydrogen fugacities between $10^{3}$ and $10^{12}$ atmospheres which can account for the elevated hydrogen concentrations observed near stress corrosion cracks [22-24].

AEM examination of crack tip oxides produced in primary water revealed both $\mathrm{NiO}$-structure and $\mathrm{NiCr}_{2} \mathrm{O}_{4}$-structure (i.e., spinel) oxides within the crack tip region. Although oxide with the $\mathrm{NiO}$-type structure is more prevalent than $\mathrm{NiCr}_{2} \mathrm{O}_{4}$, it appears that either $\mathrm{NiO}$-type or $\mathrm{NiCr}_{2} \mathrm{O}_{4}$ could be significant sources of hydrogen, according to the following explanation. Inspection of Figures 26 and 27 shows that while $\mathrm{NiCr}_{2} \mathrm{O}_{4}$ can produce high hydrogen fugacities, the formation of pure $\mathrm{NiO}$ produces low hydrogen fugacity $(0.62 \mathrm{~atm})$ and low stress-enhanced hydrogen concentrations ( $<10 \mathrm{wt}$. ppm) for both Alloy X-750 and Alloy 600. However, chemical analysis of the crack tip oxides shows that while the predominant crack tip oxide has the $\mathrm{NiO}$ structure, the actual oxide was consistently found to contain oxidized $\mathrm{Cr}$ and $\mathrm{Fe}$ $(\mathrm{Ni}, \mathrm{Cr}, \mathrm{Fe}) \mathrm{O}$, consistent with prior work [4]. 


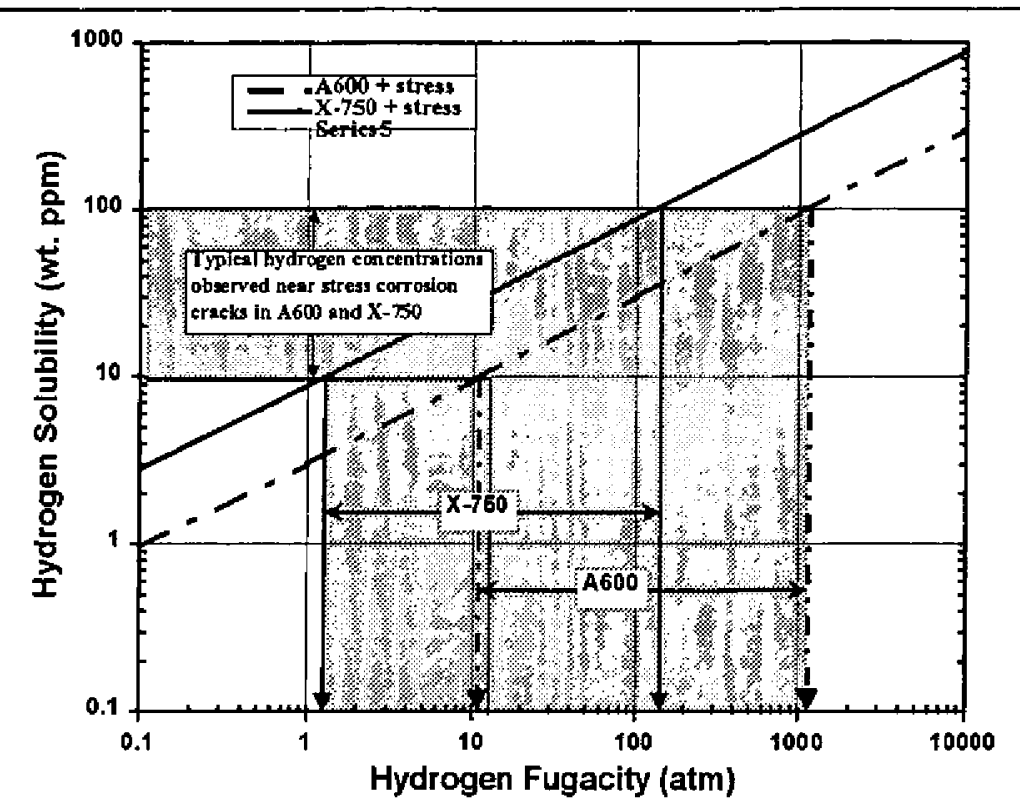

Figure 27. Illustration of the hydrogen fugacity required to dissolve 10-100 wt. ppm hydrogen in Alloy 600 and Alloy $\mathrm{X}-750$ at $360^{\circ} \mathrm{C}$. Note that an upper bound effect of stress has been included in the solubility calculations.

As shown in Figure 27, the oxidation of $\mathrm{Fe}$ and $\mathrm{Cr}$ to produce $\mathrm{Fe}_{3} \mathrm{O}_{4}, \mathrm{NiCr}_{2} \mathrm{O}_{4}$, and $\mathrm{Cr}_{2} \mathrm{O}_{3}$ (reactions $\mathrm{f}, \mathrm{g}$, and $\mathrm{h}$ in Figure 26) can result in high ( $>100 \mathrm{~atm}$ ) fugacities of hydrogen and can account for the 10 to $100 \mathrm{wt}$. ppm of hydrogen observed near stress corrosion cracks [22-24]. Of the oxidation reactions that can produce high hydrogen fugacities, the $\mathrm{Cr}$-rich spinel is more commonly observed in near-neutral hydrogenated water (Table IV) than $\mathrm{Fe}_{3} \mathrm{O}_{4}$ or $\mathrm{Cr}_{2} \mathrm{O}_{3}$, and is therefore more likely to influence SCC. It is also possible that oxidation to form a mixed $(\mathrm{Ni}, \mathrm{Cr}, \mathrm{Fe}) \mathrm{O}$ oxide results in a significantly higher hydrogen fugacity than pure $\mathrm{NiO}$ formation. The possible influence of an $\mathrm{NiO}$-structure oxide containing $\mathrm{Cr}$ and $\mathrm{Fe}$ on $\mathrm{SCC}$ is consistent with the findings of Yonezawa et al. [23] and Morton et al. [6] who observed maximum hydrogen concentrations and SCCGRs, respectively, near the $\mathrm{Ni} / \mathrm{NiO}$ phase transition in Alloy X-750.

Hence, for a hydrogen-assisted cracking mechanism to be viable, analysis of literature data and the AEM examination of the crack tip oxides performed in this study indicates that:

(1) Hydrogen must be generated via corrosion,

(2) The likely source of hydrogen is either corrosion to produce $\mathrm{NiC}_{2} \mathrm{O}_{4}$ or an NiO-type oxide structure with mixed $(\mathrm{Ni}, \mathrm{Cr}, \mathrm{Fe}) \mathrm{O}$ composition, and

(3) The fugacity of hydrogen generated by the production of $(\mathrm{Ni}, \mathrm{Cr}, \mathrm{Fe}) \mathrm{O}$ at $360^{\circ} \mathrm{C}$ must be significantly greater than that of $\mathrm{Ni} / \mathrm{NiO}(0.62 \mathrm{~atm})$; likely $>10 \mathrm{~atm}$.

It is also important to note that in addition to the three requirements listed above, it needs to be demonstrated that locally high hydrogen concentrations exist in the crack tip process zone and are not simply the result of the cathodic reaction that balance an anodic dissolution based mechanism of crack advance. Without better understanding of the spatial distribution of hydrogen (i.e. ahead of the crack tip or in the crack wake), both hydrogen-assisted and anodic dissolution based mechanisms (e.g., FRO) remain viable mechanisms for SCC in primary water. 


\section{Carbide Oxidation/Stability}

A Pourbaix diagram for chromium carbides in water at $327^{\circ} \mathrm{C}$ has been assembled by Staehle [32]; an excerpt from this diagram is shown in Figure 28. Although this diagram was constructed for $\mathrm{Cr}_{23} \mathrm{C}_{6}$, it is considered to be a reasonable approximation of the diagram for $\mathrm{Cr}_{7} \mathrm{C}_{3}$ [33]; it is also noted that some degree of approximation in applying this diagram to the present work arises from the fact that the test temperatures in this study (i.e., 260 to $399^{\circ} \mathrm{C}$ ) are somewhat different than $327^{\circ} \mathrm{C}$. In this diagram, it is clear that, over a relatively large range of $\mathrm{pH}$ and $\mathrm{EcP}, \mathrm{Cr}$ carbides are not thermodynamically stable in water. In fact, the observation that $\mathrm{Cr}$ carbides can oxidize (e.g., to $\mathrm{Cr}_{2} \mathrm{O}_{3}$ ) is consistent with the thermodynamic data in Figure 28. However, in most environments (e.g., near-neutral water, acidic environments) it is typical to find only a thin layer of oxide (typically $\sim 2$ to $5 \mathrm{~nm}$, but up to $20 \mathrm{~nm}$ in some cases) around the carbides, while the rest of the carbide remains intact (Figure 17). Due to the relatively thin nature of the oxide, diffraction studies have so far been unable to identify its crystal structure. The common observation of this thin layer of oxide around carbides, in conjunction with Figure 28, suggests that in many environments (e.g., near-neutral hydrogenated and mildly acidic oxidizing), the oxidation of $\mathrm{Cr}$ carbides may be thermodynamically stable but kinetically slow, likely due to the protective nature of oxide which often forms around the carbide. The fact that some carbides appear to be oxidized in the steam test may be due to more rapid oxidation kinetics at the higher temperature $\left(399^{\circ} \mathrm{C}\right)$, to the relatively long exposure time $(\sim 600$ days), or perhaps the oxidation is more favorable in a steam environment than in an aqueous environment.

Unlike in the near-neutral water or acidic environments, the kinetics of carbide oxidation in the caustic environment appear to be fairly rapid, since relatively large carbides $\left(\sim 0.5 \mu \mathrm{m} \mathrm{M} \mathrm{M}_{7} \mathrm{C}_{3}\right.$ carbides) were completely oxidized in a test which lasted for only $\sim 42$ days. This observation is also consistent with Figure 28, as the solubility of $\mathrm{Cr}$ in caustic appears to be greater than in near-neutral or acidic expected crack tip environments. In fact, the caustic test was conducted in a regime bordering the stability domain of $\mathrm{Cr}$ oxyanions (e.g., $\mathrm{CrO}_{4}{ }^{2-}, \mathrm{Cr}_{2} \mathrm{O}_{7}{ }^{2-}$ ), indicating higher solubility in caustic.

\section{Application of AEM: An Example}

One practical use of AEM is to establish the environmental conditions under which SCC occurred. As an example, it was suggested by Staehle [19] that the recent occurrence of Alloy 600 secondary-side SCC at the Oconee plant [34] may have been caused by high oxygen conditions at startups. This suggestion can be evaluated to some degree by comparing the oxidizing, mildly acidic test specimen evaluated in the present work to the Oconee AEM work of Thomas and Bruemmer [17]. In that study, the presence of fully oxidized carbides in the crack wake was very evident. From the present work, it appears that this morphology is more consistent with caustic exposure, or perhaps with the steam exposure, than with the aerated, mildly acidic environment exposure. However, this comparison is not definitive, since it cannot be ruled out that cracking could have occurred in an aerated environment at startup, with oxidation of the crack wake carbides occurring during subsequent superheated conditions (i.e., steam environment) during steady-state operation. An additional caveat is that oxidation kinetics could be playing a role. In other words, since the oxidation of carbides appears thermodynamically favorable but kinetically slow in many environments, it is possible that carbides in the Oconee tubing, which was in service for $\sim 17$ effective full power years [34], could have been oxidized by long time exposure to any number of possible environments. Most cracks which have been examined by AEM in the present work, and in prior work $[4,8-13]$ were 


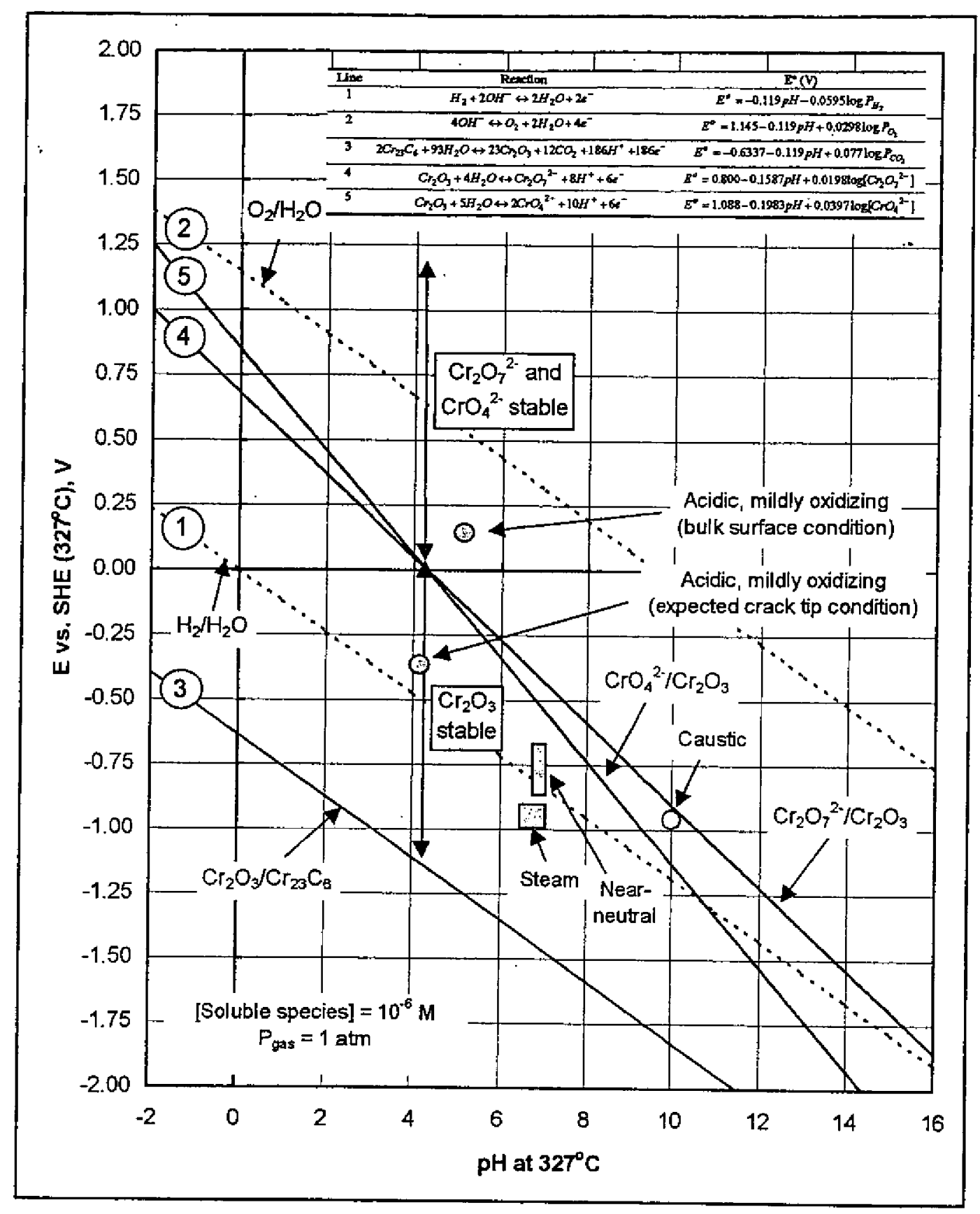

Figure 28. Pourbaix diagram for chromium carbide stability [Staehle]. 
subjected to exposures of less than a year. A complication to the exposure time issue is that kinetic processes are often accelerated by temperature, such that a 1 year exposure at an elevated temperature test condition $\left(e . g ., 360\right.$ or $399^{\circ} \mathrm{C}$ ) may be equivalent to a multi-year exposure at lower temperatures.

\section{Conclusions}

1. AEM of stress corrosion cracks provides critical information into the morphology, structure, and composition of crack wake and crack tip oxides which helps identify the environmental conditions under which SCC occurred.

2. Both hydrogen-assisted cracking and film-rupture/oxidation (i.e., slip-dissolution) appear to be viable mechanisms of stress corrosion crack advance in near-neutral hydrogenated water, based on AEM. However, hydrogen-assisted cracking requires corrosion to generate high hydrogen fugacities $(>1 \mathrm{~atm})$. Such conditions can be produced by corrosion to form $\mathrm{NiCr}_{2} \mathrm{O}_{4}$, and possibly a mixed $(\mathrm{Ni}, \mathrm{Cr}, \mathrm{Fe}) \mathrm{O}$ oxide with an NiO-type structure, both of which are observed via AEM in cracks produced in near neutral water.

3. No direct evidence of internal oxidation was observed in this study. Additionally, chemical species known to be present in the environment were not always detected in the analysis of oxide films exposed to the environment. This result indicates that the absence of water-borne species or impurities in an oxide does not mean that the oxide had to form via internal oxidation.

4. The mildly acidic, oxidizing test containing sulfate exhibited evidence of sulfur segregation to the crack tip, and sulfur was not detected on the bulk surface. This observation is consistent with the expected concentration of anionic species within the crack in an aerated environment.

5. The caustic crack was characterized by oxidized carbides in the crack wake but not ahead of the crack tip. This observation was shown to be consistent with the increased solubility of $\mathrm{Cr}$ as the $\mathrm{pH}$ is raised from near-neutral $(\mathrm{pH} \sim 7)$ to caustic $(\mathrm{pH} \sim 10)$.

6. In near-neutral hydrogenated water, the cracks exhibited Cr-rich spinels and NiO-type oxides but no significant oxidation of grain boundary carbides. Dissolved hydrogen affected the CGR, but showed no apparent effect on the AEM morphology of the crack.

7. In hydrogenated steam, metallic nickel nodules were evident in both the crack wake and on the specimen surface. Single crystal, spinel-structure oxide particles having a similar size and shape to the microstructural carbides were found in the crack wake. It is likely that these particles represent carbides that were oxidized by contact with the steam.

\section{Acknowledgements}

Mark Ando performed the SCCGR testing and Paul Sander performed some of the diffraction measurements. Thanks also to Dr. Ernie Hall of General Electric Corporate Research and Development Center for conducting the $\mathrm{Cr}$ depletion measurements and to Dr. Roger Staehle for permitting the use of the chromium carbide Pourbaix diagram.

\section{References}

1. R.W. Staehle, "Understanding 'Situation Dependent Strength': A Fundamental Objective in Assessing the History of Stress Corrosion Cracking", in Environment-Induced Cracking of Metals (NACE-10), R.P. Gangloff and M.B. Ives, eds., pp. 561-612, 1988.

2. S.M. Bruemmer, V.Y. Gertsman, and L.E. Thomas, "High Resolution Comparison of Primary- and Secondary-Side Intergranular Degradation in Alloy 600 Steam Generator Tubing”, CORROSION/2000, Paper No. 196. 
3. D.S. Morton, D. Gladding, and M.K. Schurman, "Effect of Soluble Zinc Addition on the SCC Performance of Nickel Alloys in Deaerated Hydrogenated Water", Proceedings of the Eighth International Symposium on Environmental Degradation of Materials in Nuclear Power Systems, p. 387, August 1997.

4. J.S. Fish, N. Lewis, W. Yang, D.J. Perry and C.D. Thompson, "AEM Investigations of Primary Water SCC in Nickel Alloys", Proceedings of the Eighth International Symposium on Environmental Degradation of Materials in Nuclear Power Systems, $p$. 266, August 1997.

5. S.A. Attanasio, J.S. Fish, W.W. Wilkening, P.M. Rosecrans, and D.S. Morton, "Measurement of the Fundamental Parameters for the Film-Rupture/Oxidation Mechanism - The Effect of Chromium", Proceedings of the Ninth International Symposium on Environmental Degradation of Materials in Nuclear Power Systems, August 1999.

6. D.S. Morton, S.A. Attanasio, and M.K. Schurman, "Influence of Dissolved Hydrogen on Nickel Alloy SCC in High Temperature Water", CORROSION/99, Paper No. 447.

7. R Fernandez-Prini and R Crouetto, "Evaluation Data on Solubility of Simple Apolar Gases in Light and Heavy Water at High Temperature", J. Phys Chem. Vol. 18, pp. 1231, 1989

8. N. Lewis, B.W. Bussert, and M.L. Bunch, "Cross-Sectional AEM Analysis of SCC Cracks", EPRI Steam Generator IGA/SCC Workshop, San Antonio, TX, December 8 10, 1992.

9. B.W. Bussert, N. Lewis, I. Goldberg, R. Keefer, "An Integrated Approach to Investigating Stress Corrosion Cracking", EPRI Alloy 600 PWSCC Experts Meeting, Warrenton, VA, April 6-9, 1993

10. C.D. Thompson, N. Lewis, and H.T. Krasodomski, "Analysis of Alloy 600 and X-750 Stress Corrosion Cracks", EPRI Alloy 600 Experts Meeting, Airlie House, Warrenton, VA, April 6-9, 1993.

11. C.D. Thompson, H.T. Krasodomski, N. Lewis, and G.L., Makar, "Prediction of PWSCC in Nickel Base Alloys Using Crack Growth Rate Models", Proceedings of the Seventh International Symposium on Environmental Degradation of Materials in Nuclear Power Systems, p. 867, August 1995.

12. H.T. Krasodomski, J.S. Fish, N. Lewis, and W.J. Yang, "Analysis of PWSCC Initiation and Crack Growth in Laboratory Specimens and Components as a Function of Material Condition", EPRI Workshop on PWSCC of Alloy 600 in PWRs, Daytona Beach, FL, February 25-27, 1997.

13. N. Lewis, D.J. Perry, and M.L. Bunch, "AEM Analysis of Stress Corrosion Cracks", Proceedings of Microscopy and Microanalysis, p. 550, 1995.

14. W.C. Moshier and C.M. Brown, "Effect of Cold Work and Processing Orientation on the SCC Behavior of Alloy 600", CORROSION/99, Paper No. 449.

15. T. Cassagne, F. Vaillant, and P. Combrade, "An Update on the Influence of Hydrogen on the PWSCC of Nickel Base Alloys in High Temperature Water", Proceedings of the Eighth International Symposium on Environmental Degradation of Materials in Nuclear Power Systems, p. 307, August 1997.

16. PL Andresen and LM Young, "Crack Tip Microsampling and Growth Rate Measurements in Low-Alloy Steel in High Temperature Water", Corrosion, Vol. 51, March 1995.

17. L.E. Thomas and S.M. Breummer, "Insights into Crack Growth Mechanisms from Analytical Transmission Electron Microscopy of SCC Crack Tips", Proceedings of the Ninth International Symposium on Environmental Degradation of Materials in Nuclear Power Systems, August 1999. 
18. P.M. Scott, Proceedings of the Ninth International Conference on Environmental Degradation of Materials in Nuclear Power Systems, Newport Beach, August 1999, in press.

19. R.W. Staehle and Z. Fang, "Comments on a Proposed Mechanism of Intemal Oxidation for Alloy 600 as Applied to Low Potential SCC", Proceedings of the Ninth International Symposium on Environmental Degradation of Materials in Nuclear Power Systems, August 1999.

20. FP Ford and PL Andresen, "Development and Use of a Predictive Model of Crack Propagation in $304 / 316 \mathrm{~L}$, A533B/A508 and Inconel $600 / 182$ in $288^{\circ} \mathrm{C}$ Water", Proceedings of the Third International Conference on Environmental Degradation of Materials in Nuclear Power Systems - Water Reactors, G.J. Theus and J.R. Weeks eds., TMS, 1987, pp. 691-696.

21. P.L. Andresen, et al., "Crack Growth Behaviors of Ni Alloys", CORROSION/2000, Paper No. 202, NACE.

22. N. Totsuka and Z. Szklarska-Smialowska, "Hydrogen Induced IGSCC of Ni-Containing FCC Alloys in High Temperature Water", Proceedings of the Third International Conference on Environmental Degradation of Materials in Nuclear Power Systems Water Reactors, G.J. Theus and J.R. Weeks eds., TMS, 1987, pp. 691-696.

23. $T$. Yonezawa, Y. Yamaguchi, and Y. Iijima, "Electron Micro-autoradiographic Observation of Tritium Distribution on Alloy X-750", Proceedings of the International Symposium on Plant Aging and Life Predictions of Corrodible Structures, May 1995, Sapporo, Japan, pp. 567-573.

24. T. Magnin et al., "Corrosion Deformation Interaction During Stress Corrosion Cracking of Alloy 600 in Primary Water, Sixth International Symposium on Environmental Degradation of Materials in Nuclear Power Systems - Water Reactors", R.E. Gold and E.P. Simonen, eds., TMS 1993, pp. 669-677.

25. S.E. Ziemniak, "Metal Oxide Solubility Behavior in High Temperature Aqueous Solutions", Journal of Solution Chemistry, Vol. 21, No. 8, pp. 745-760, 1992.

26. D.M. Symons, G.A. Young, and J.R. Scully, "The Effect of Strain on the Trapping of Hydrogen at Grain Boundary Carbides in Ni-Cr-Fe Alloys" submitted to Met. Trans., May 2000.

27. G.A. Young and J.R. Scully, "Evidence that Carbide Precipitation Produces Hydrogen Traps in Ni-17Cr-8Fe Alloys", Scripta Mat., Vol. 36, No. 6, pp. 713-719, 1997.

28. H.A. Wriedt and R.A. Oriani, "Effect of a Tensile and Compressive Elastic Stress on Equilibrium Hydrogen Solubility in a Solid", Acta Met., Vol. 18, pp. 753-760, 1970.

29. D.M. Symons, Unpublished results.

30. H. Peisel, "Lattice Strains due to Hydrogen in Metals, in Hydrogen in Metals, I.G. Alefeld and J. Volkl eds., Springer-Verlag, New York, 1978, pp. 53-74.

31. T.L. Anderson, Fracture Mechanics, CRC Press, Boca Raton, FL, 1995. pp. 130.

32. R.W. Staehle, Unpublished Results.

33. Private Communication with RW Staehle, June 2000

34. D.P. Rochester, "A TEM and SIMS Examinations of Oconee Nuclear Station Steam Generator Pulled Tubes", Proceedings of the Ninth International Symposium on Environmental Degradation of Materials in Nuclear Power Systems, August 1999. 


\section{AEM Sample Preparation}
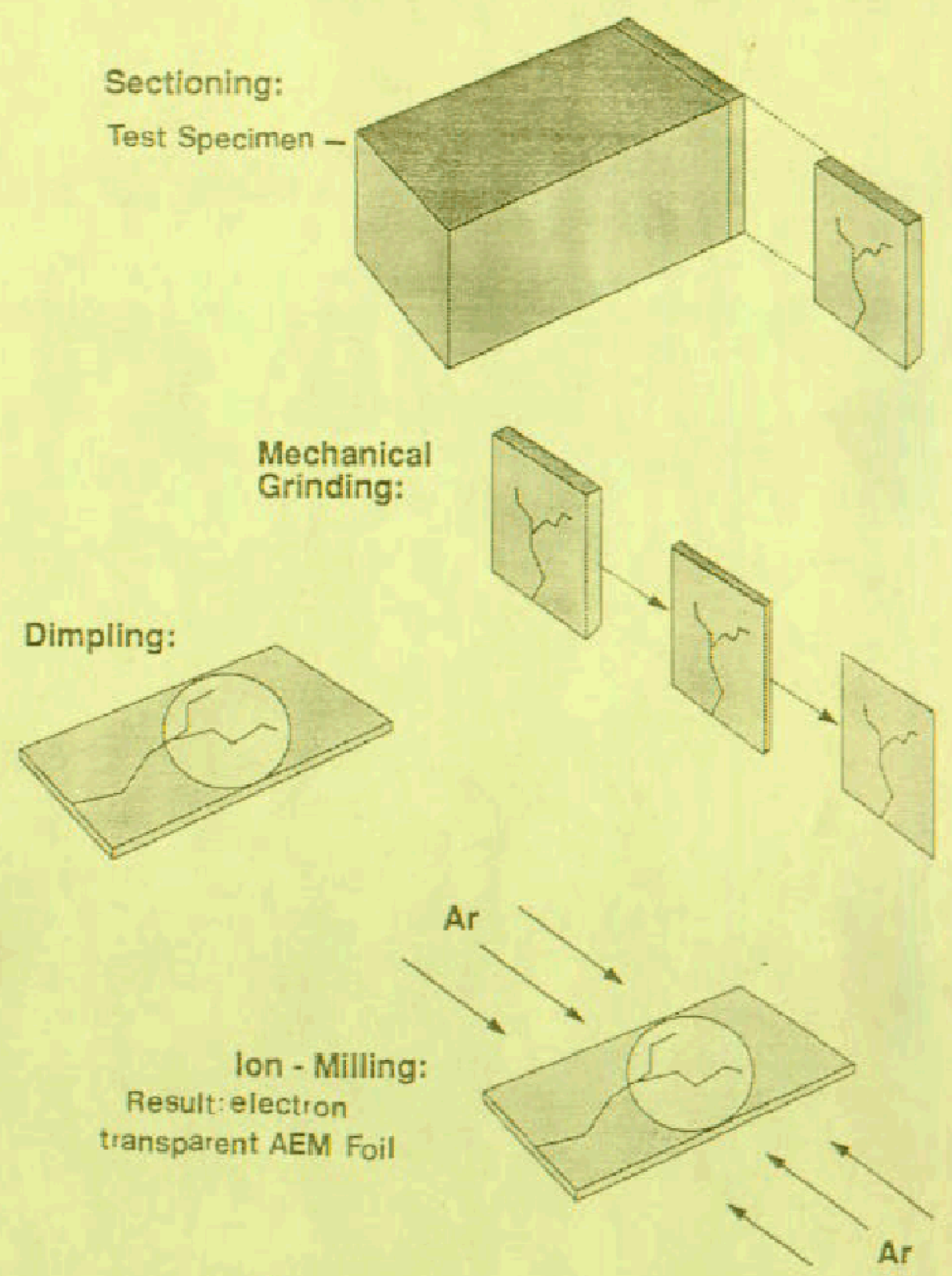

SCHEMATIC ILLUSTRATION

OF CROSS-SECTIONAL AEM SAMPLE

PREPARATION. 
Figure 3:Alloy 600 Crack Growth Rate Imposed upon the $338^{\circ} \mathrm{C}$ Nickel Pourbaix Diagram (Stress Intensity Factor of $27 \mathrm{MPa} \vee \mathrm{m}$ )

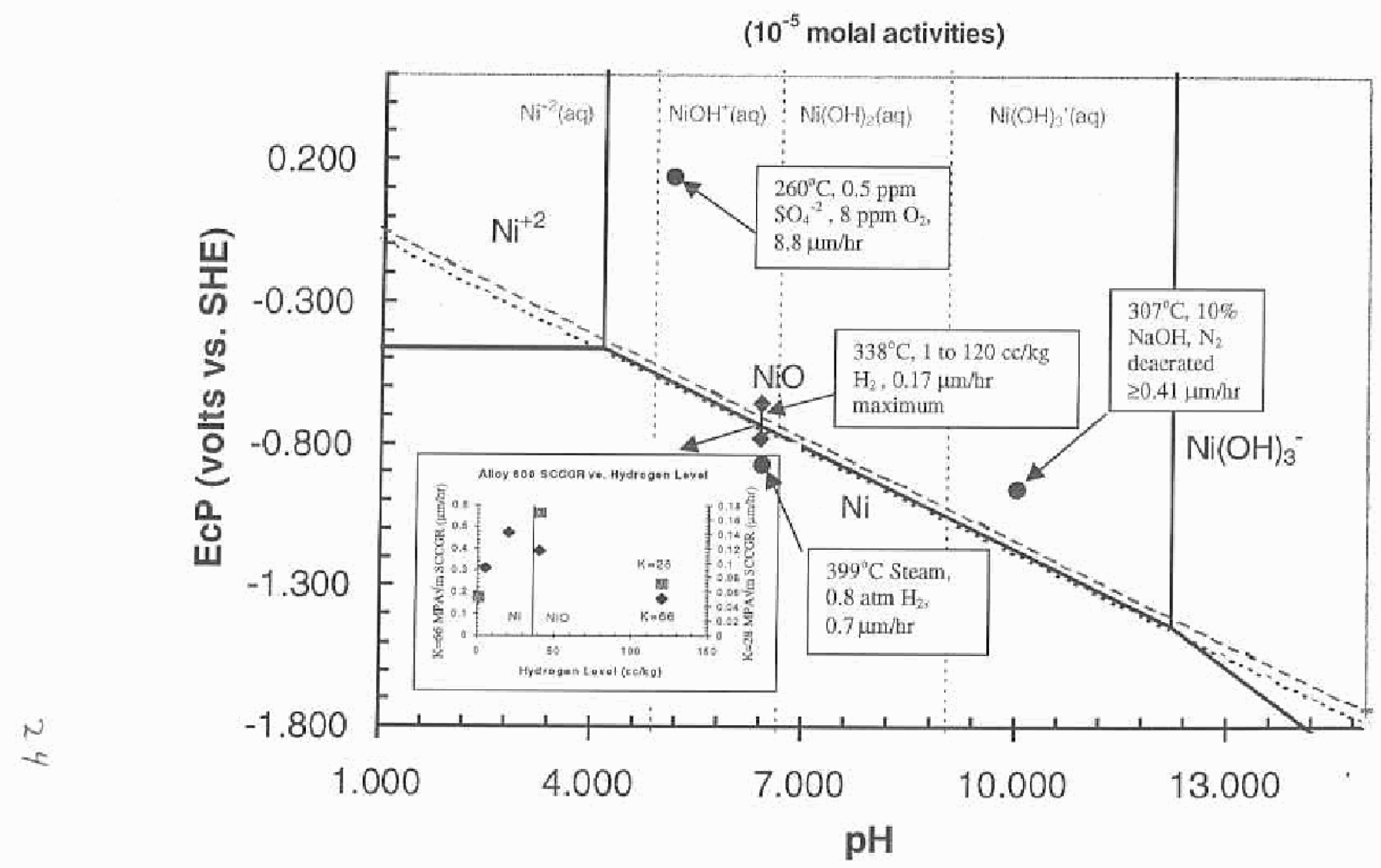




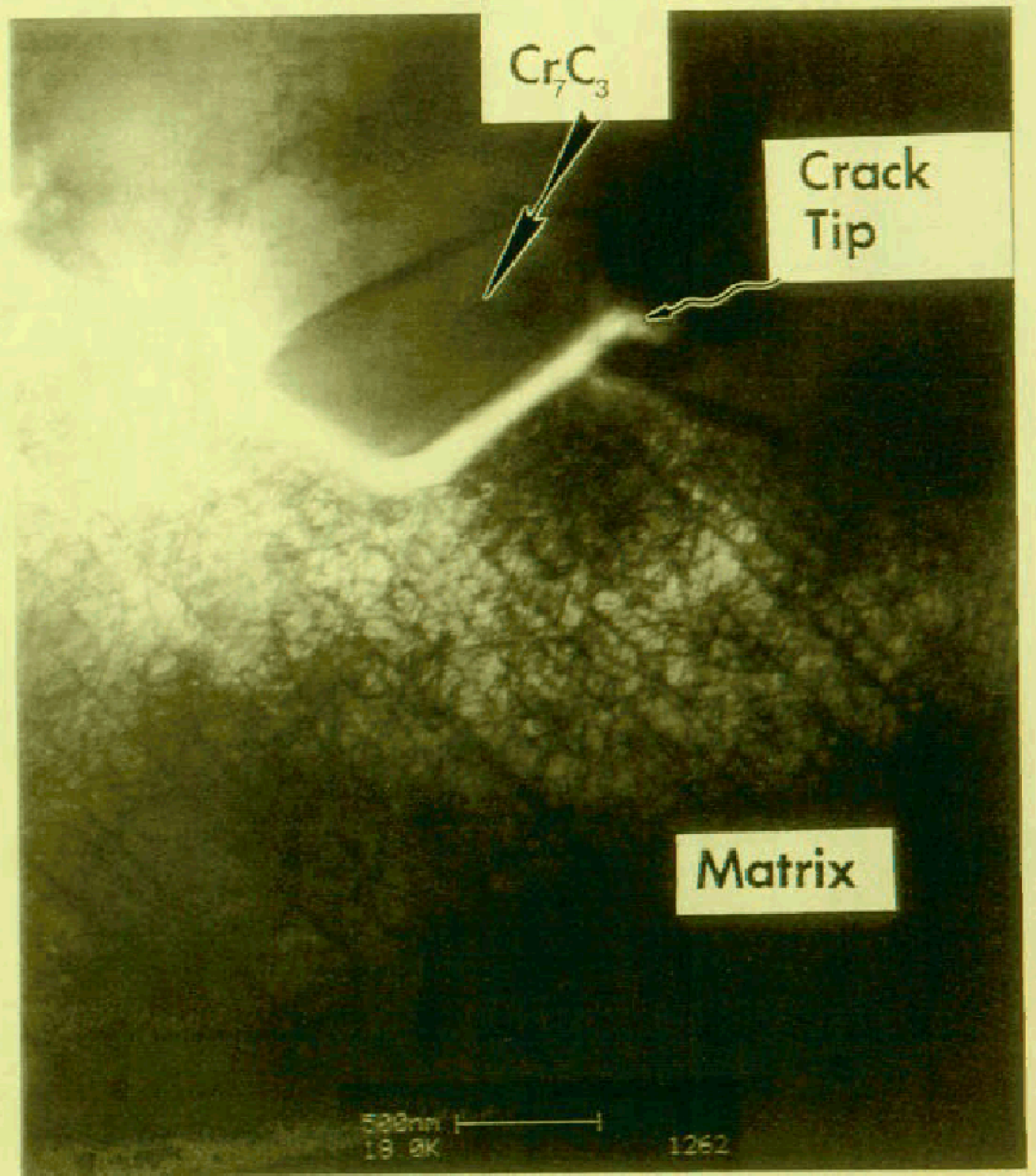

Figure 4. AEM bright field image showing cross-section of Intergranular stress corrosion crack (IGSCC) crack-tip region. $\mathrm{SCC}$ crack propagates around $\mathrm{Cr}_{7} \mathrm{C}_{3}$ carbide which remain unoxidized but still in contact with one grain. Dislocations in matrix visible in image. (Acid mildly oxiding, $260^{\circ} \mathrm{C}$, sensitized) 

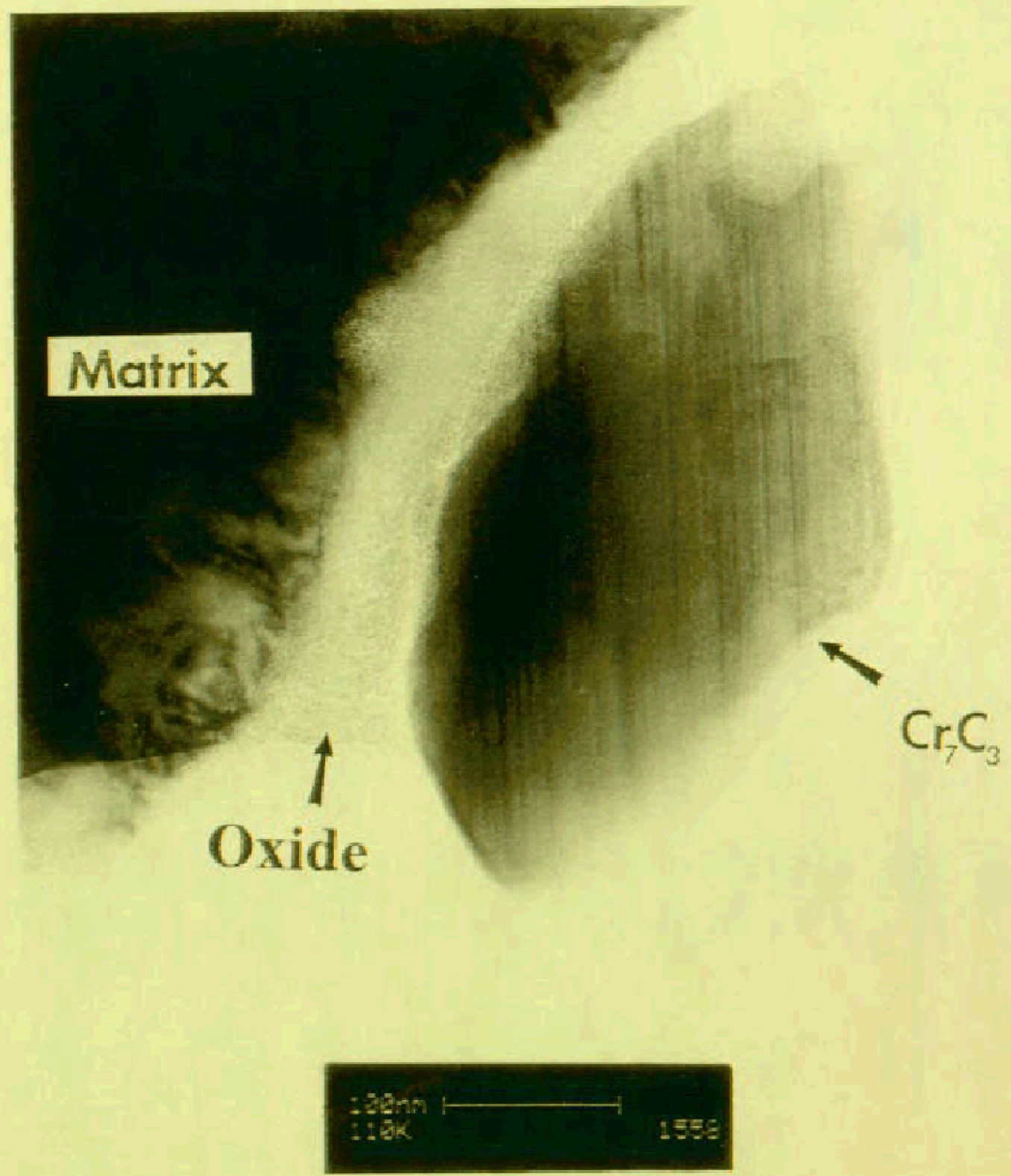

Figure 5. AEM bright field image showing cross-section of $1 \mathrm{GSCC}$ crack region. SCC crack propagates around carbide which remains unoxidized. Oxide is visible between carbide and matrix (Acid mildly oxiding, $260^{\circ} \mathrm{C}$, sensitized) 

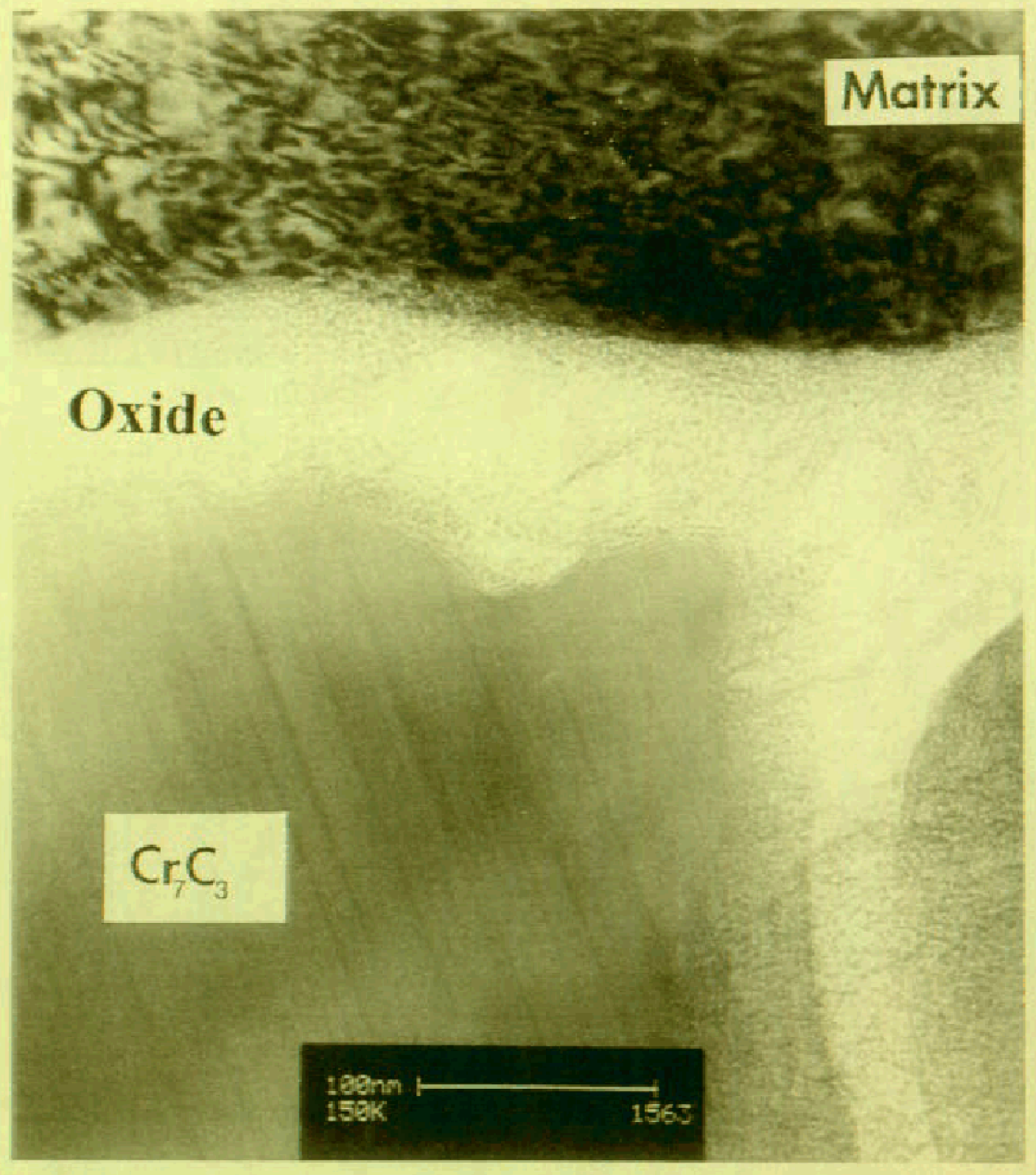

Figure 6. AEM bright field image showing cross-section of IGSCC crack. SCC crack propagates around carbide which remains unoxidized. Oxide is visible between carbide and matrix. (Acid mildly oxidizing, $260^{\circ} \mathrm{C}$, sensitized) 


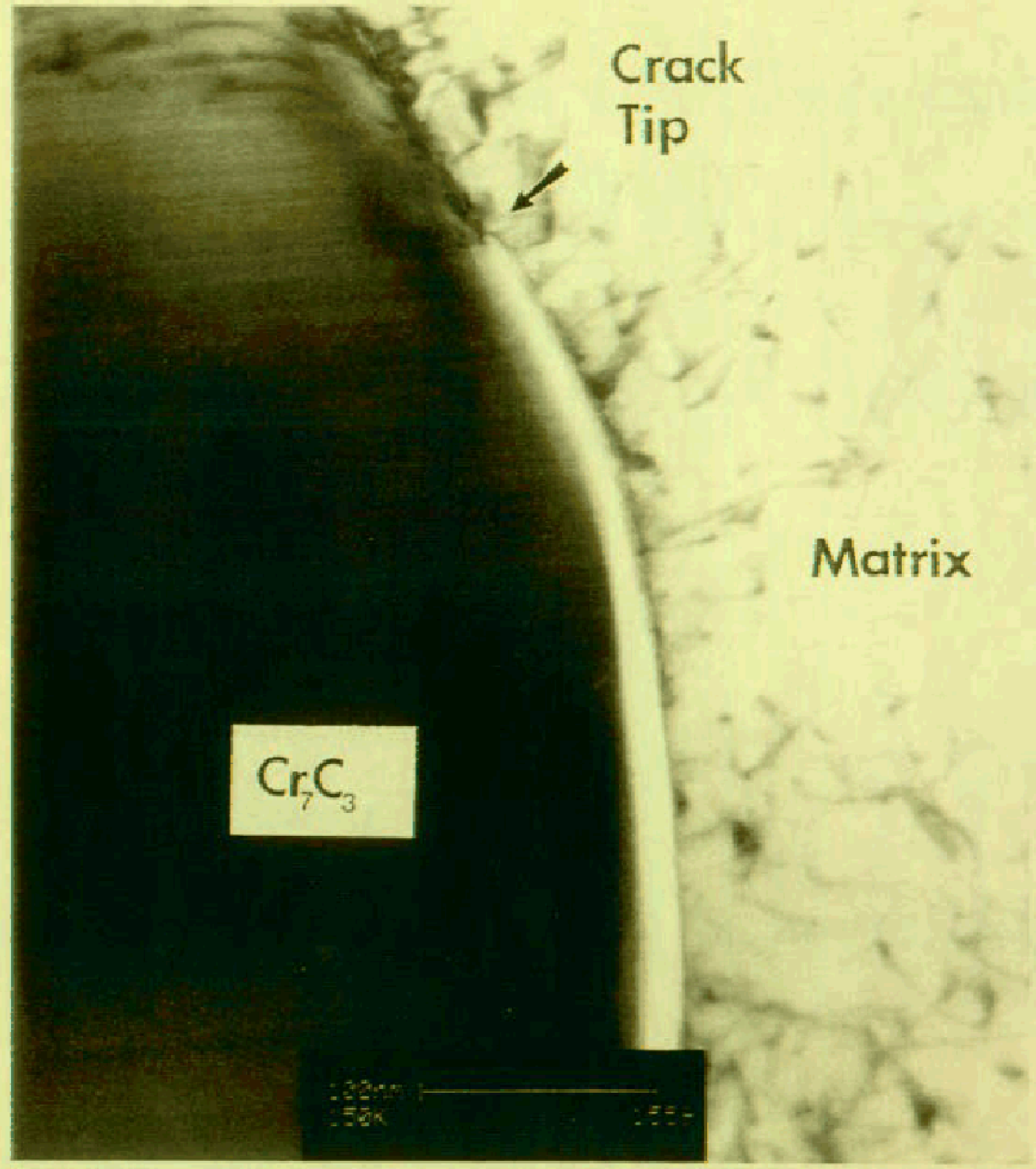

Figure 7. AEM bright field image showing cross-section of IGSCC crack-tip region. SCC crack propagates around carbide which remains unoxidized (Acid mildly oxidizing, $260^{\circ} \mathrm{C}$, sensitized) 


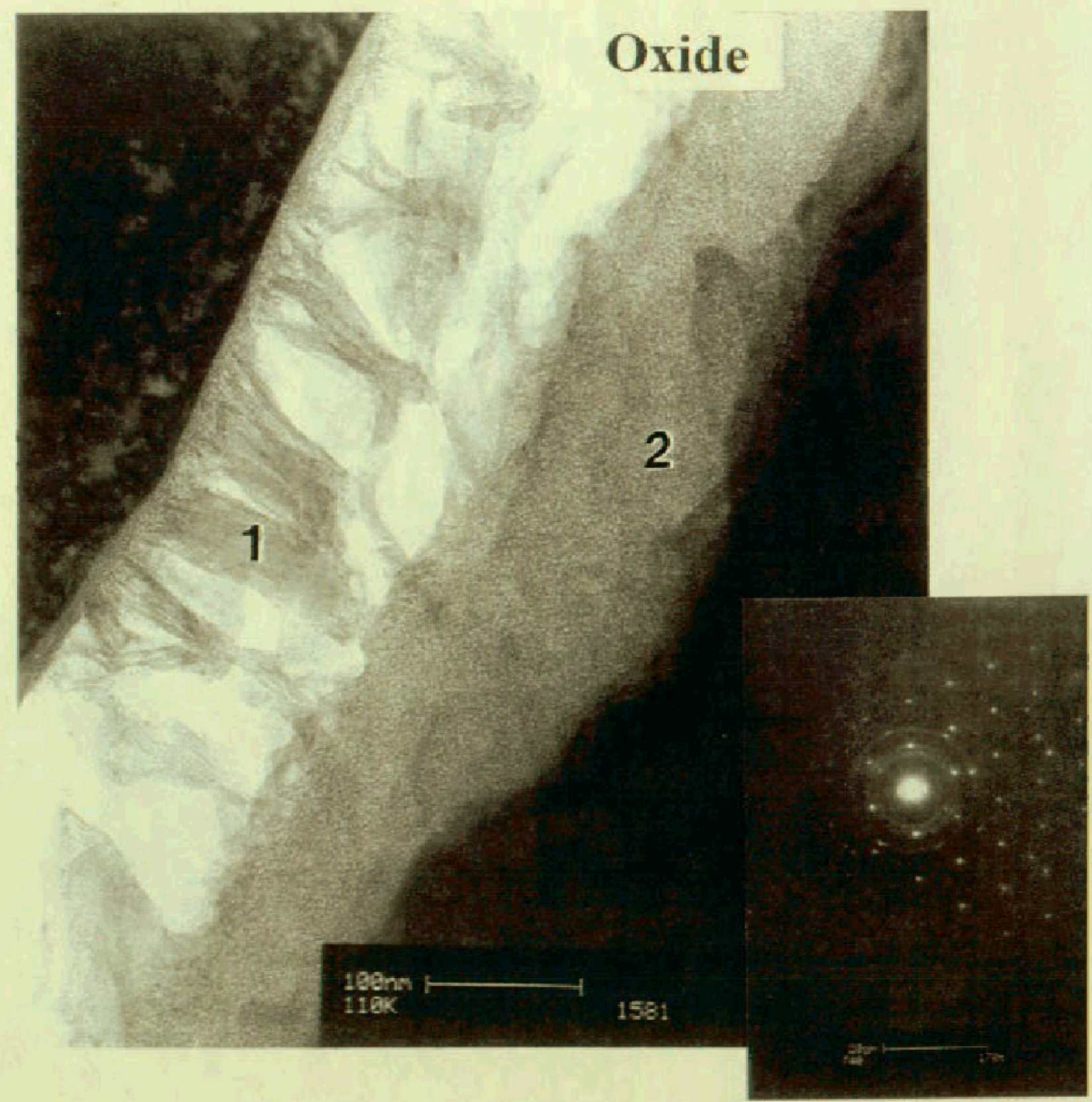

Figure 8. AEM bright field image showing cross-section of wide IGSCC crack away from carbides. Oxide corrosion product exhibits speckled and acicular morphologies. Electron diffraction pattern contains some $\mathrm{NiO}$ and unidentified textured phase. (Acid mildly oxiding, $260^{\circ} \mathrm{C}$, sensitized) 


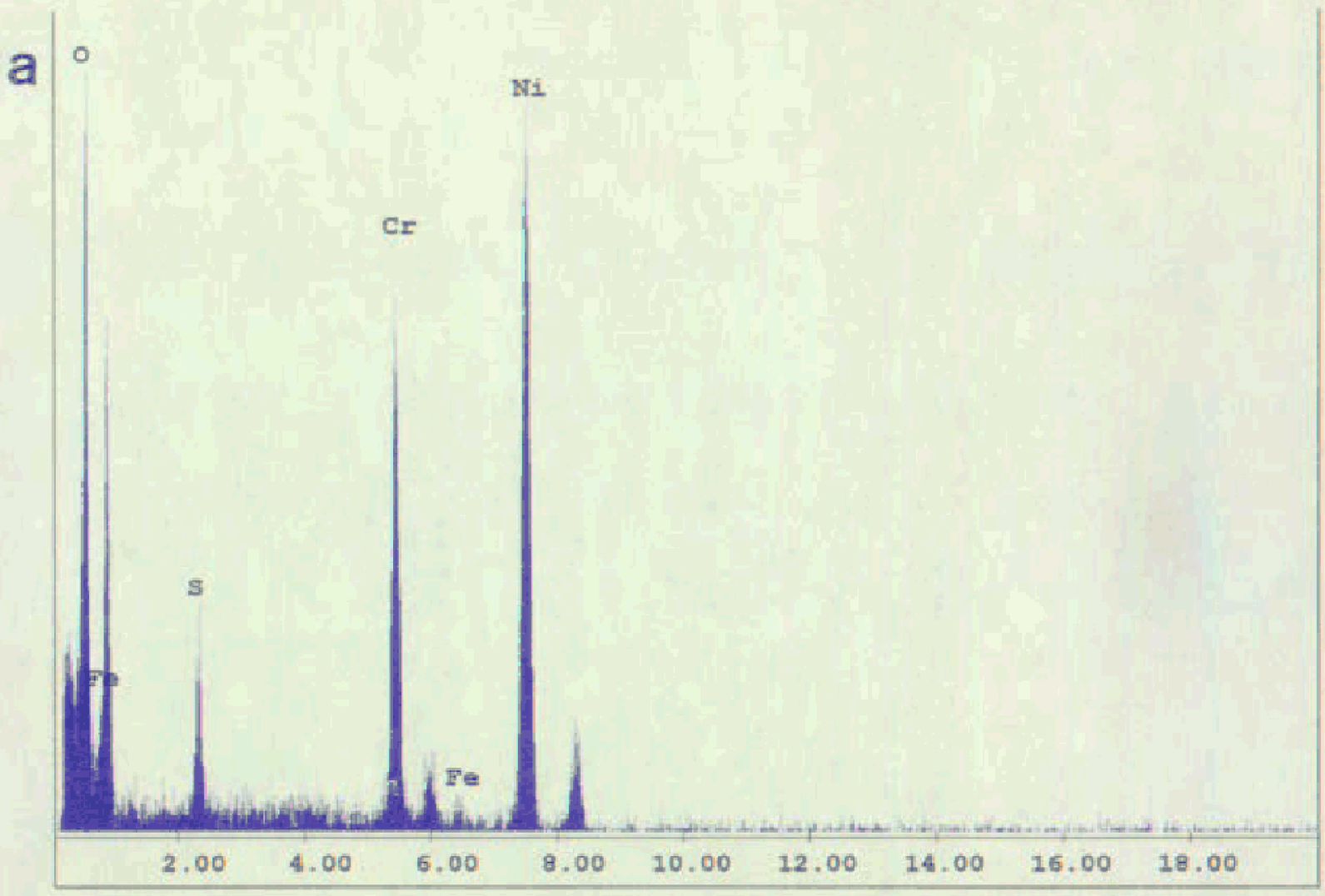

Figure 9. a) X-ray spectrum from area 1 in Figure 8 showing high $\mathrm{Ni}, \mathrm{Cr}$ and $\mathrm{S}$. b) $\mathrm{X}$-ray spectrum from area 2 in Figure 8 showing higher $\mathrm{Cr}$ than $\mathrm{Ni}$ and some $\mathrm{Ti}$. (Acid mildly oxidizing, $260^{\circ} \mathrm{C}$, sensitized). 


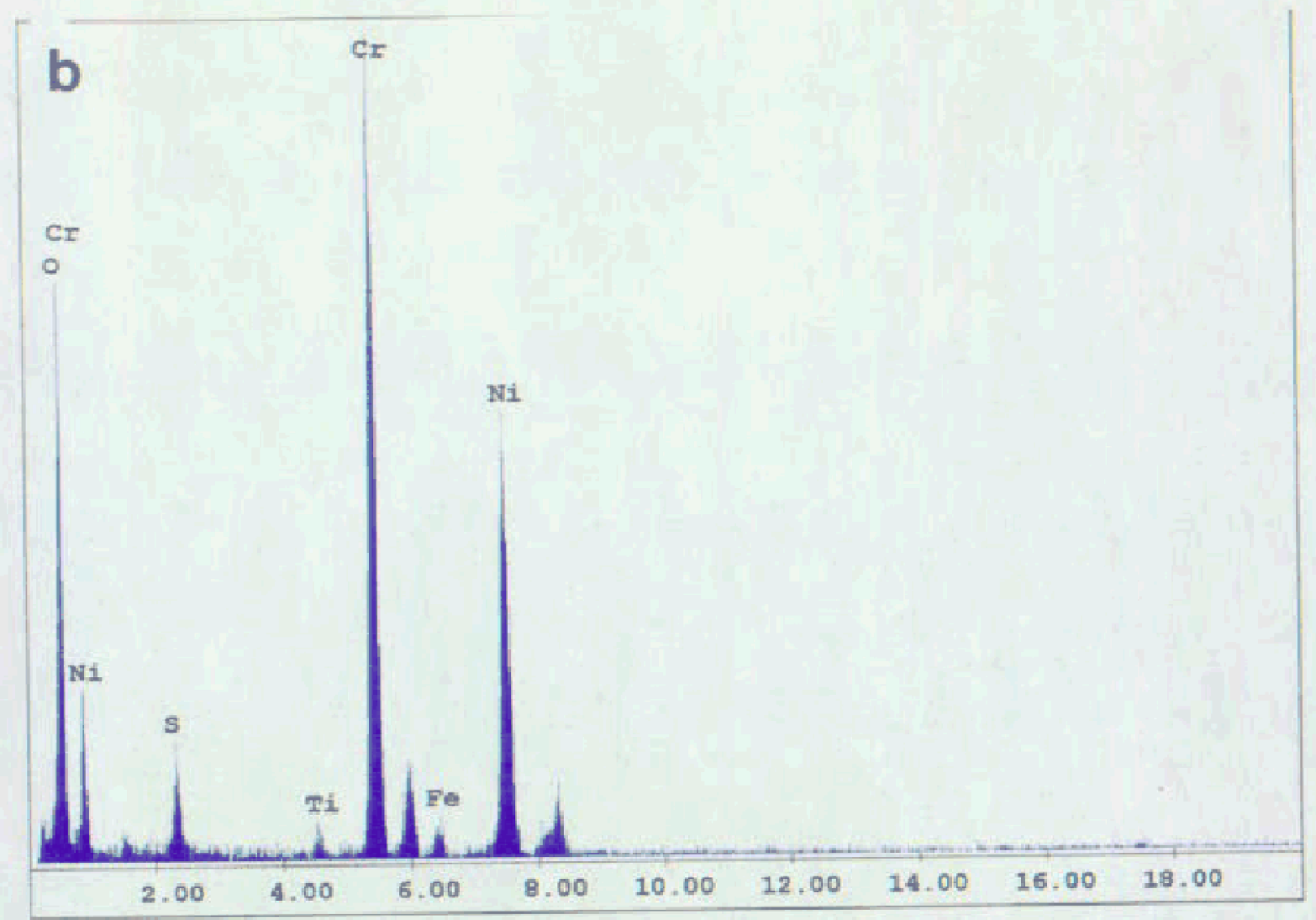

Figure 9. a) X-ray spectrum from area 1 in Figure 8 showing high $\mathrm{Ni}, \mathrm{Cr}$ and $\mathrm{S}$. b) $\mathrm{X}$-ray spectrum from area 2 in Figure 8 showing higher $\mathrm{Cr}$ than $\mathrm{Ni}$ and some $\mathrm{Ti}$. (Acid mildly oxidizing, $260^{\circ} \mathrm{C}$, sensitized) 

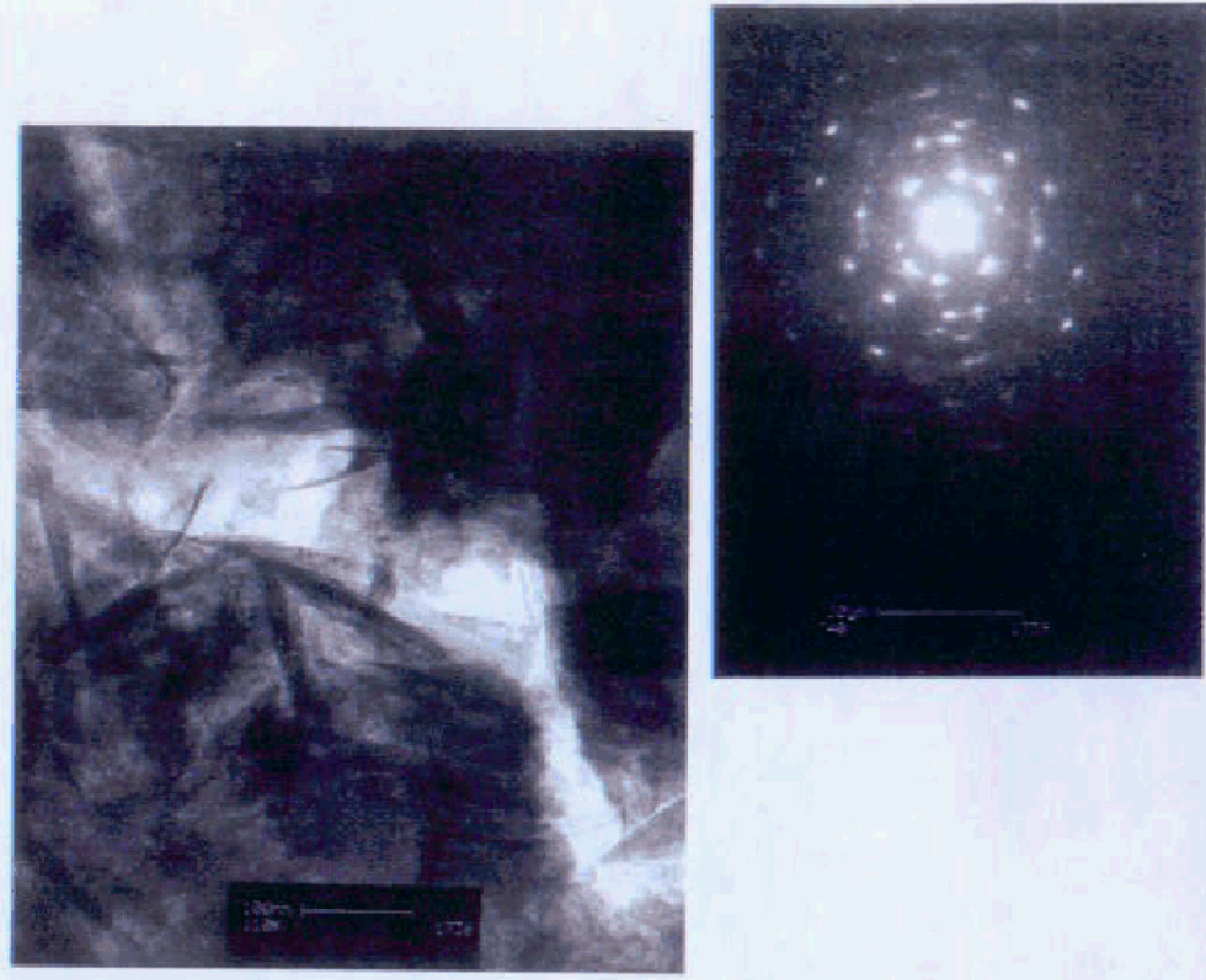

Cr

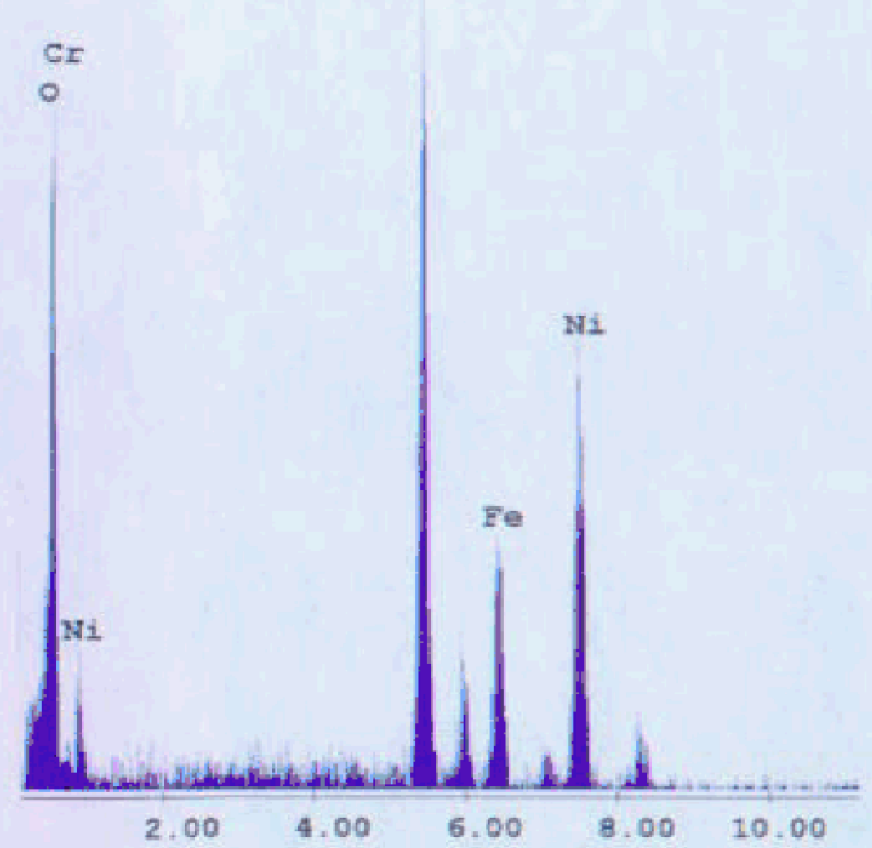

CI
○

CI

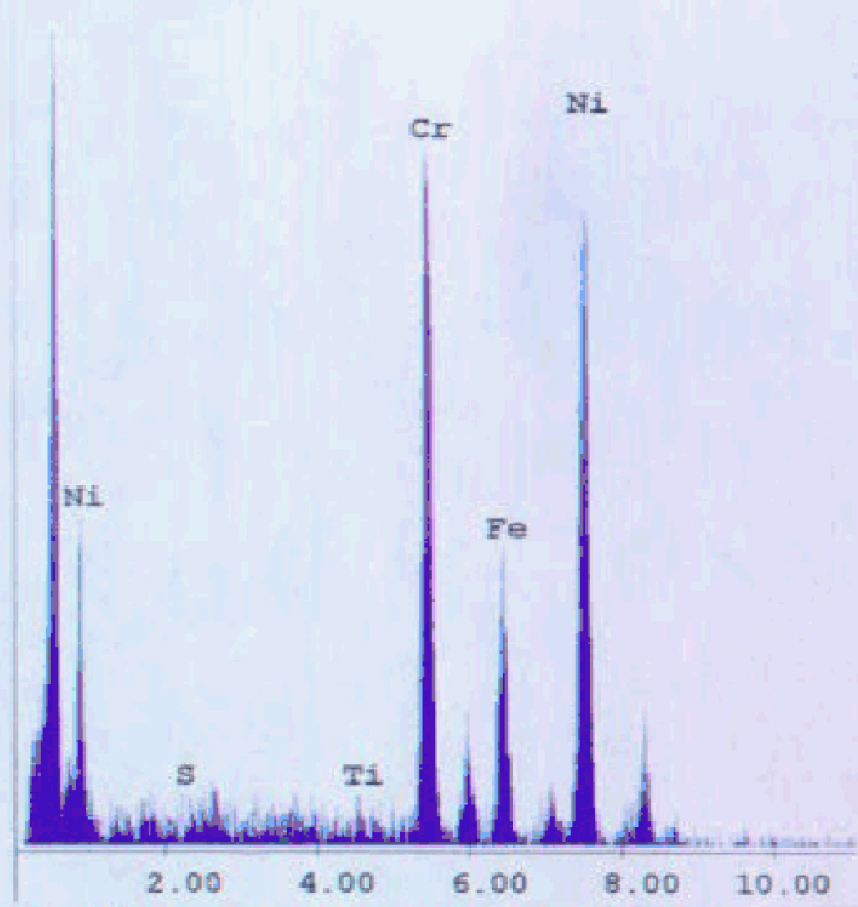

Figure 10. AEM bright field image and corresponding $\mathrm{x}$-ray spectrum showing acicular structure in planar section of bulk oxide. Oxide is enriched in $\mathrm{Cr}$ but contains significant $\mathrm{Ni} F e$ and $\mathrm{Cr}$. Electron diffraction pattern indexes to $\mathrm{CrOOH}$ (Acid mildly oxidizing, $260^{\circ} \mathrm{C}$, sensitized). 

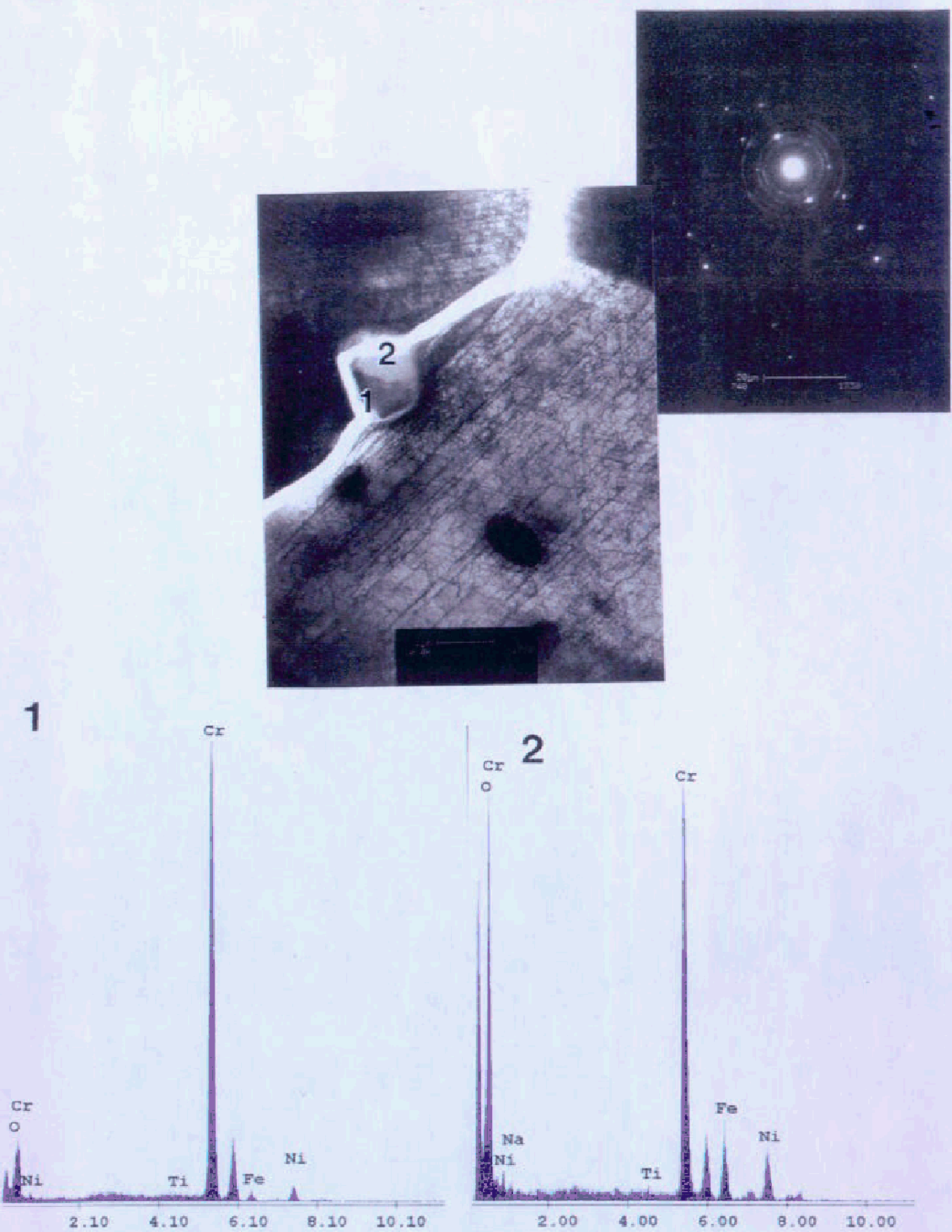

Figure 11. AEM bright field image and corresponding $\mathrm{x}$-ray spectrum showing IGSCC crack propagating around partially oxidized carbide. Dislocation structure visible in matrix. Spectrum 1 is from carbide, spectrum 2 is from oxidized portion of carbide. Oxide is enriched in Fe and $\mathrm{Ni}$ relative to carbide. Some $\mathrm{Na}$ observed in this region. Electron diffraction pattern indexes to $\mathrm{Cr}_{2} \mathrm{O}_{1}$ (caustic. $307^{\circ} \mathrm{C}$. healed) 


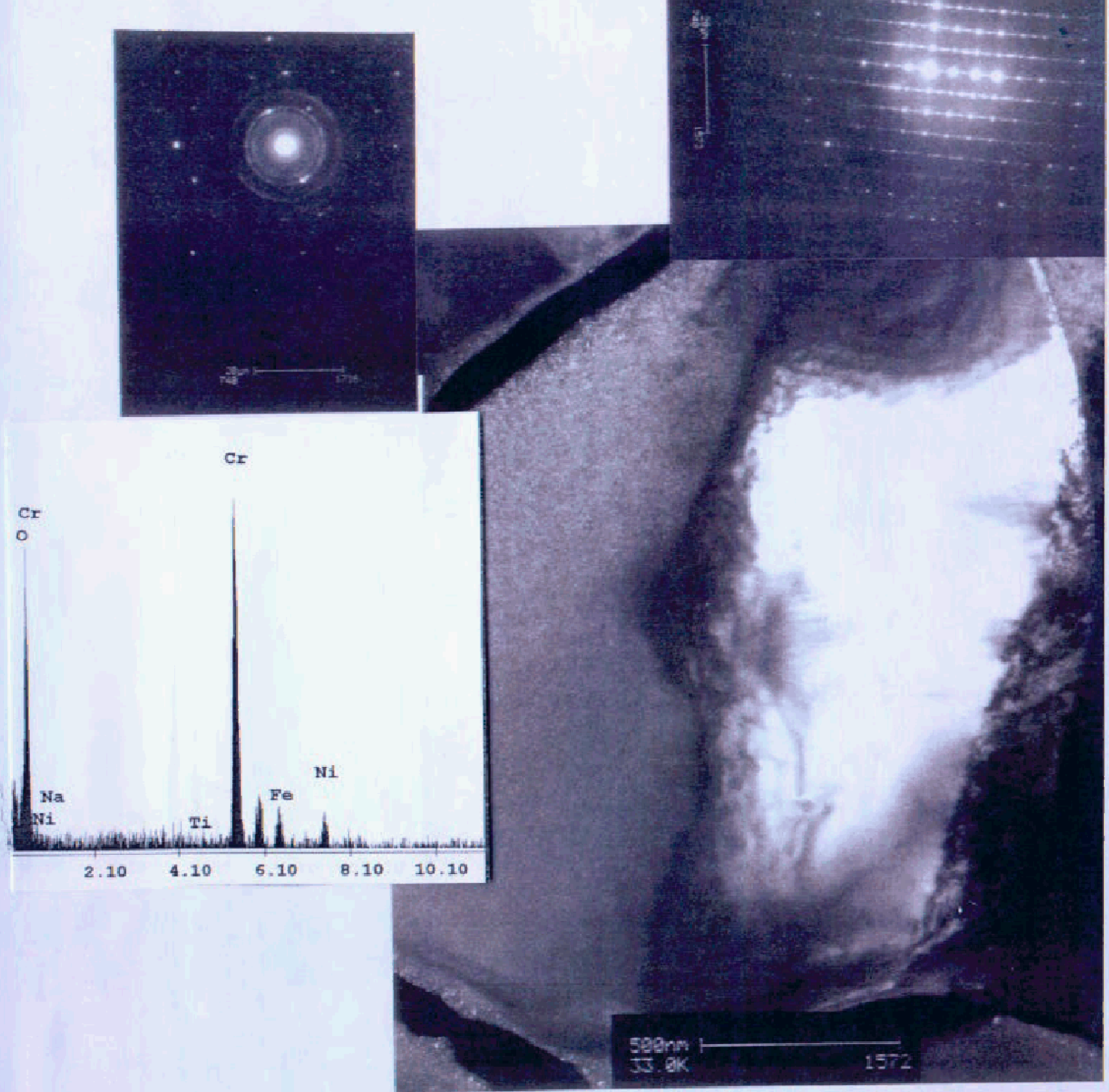

Figure 12. AEM dark field image (carbide reflection) showing IGSCC crack propagating around partially oxidized carbide. Bright area is single crystal $\mathrm{Cr}_{7} \mathrm{C}_{3}$, speckled area is $\mathrm{Cr}$ rich polycrystalline structure consistent with spinel but diffraction rings are weak and diffuse (caustic, $307^{\circ} \mathrm{C}$, healed) 


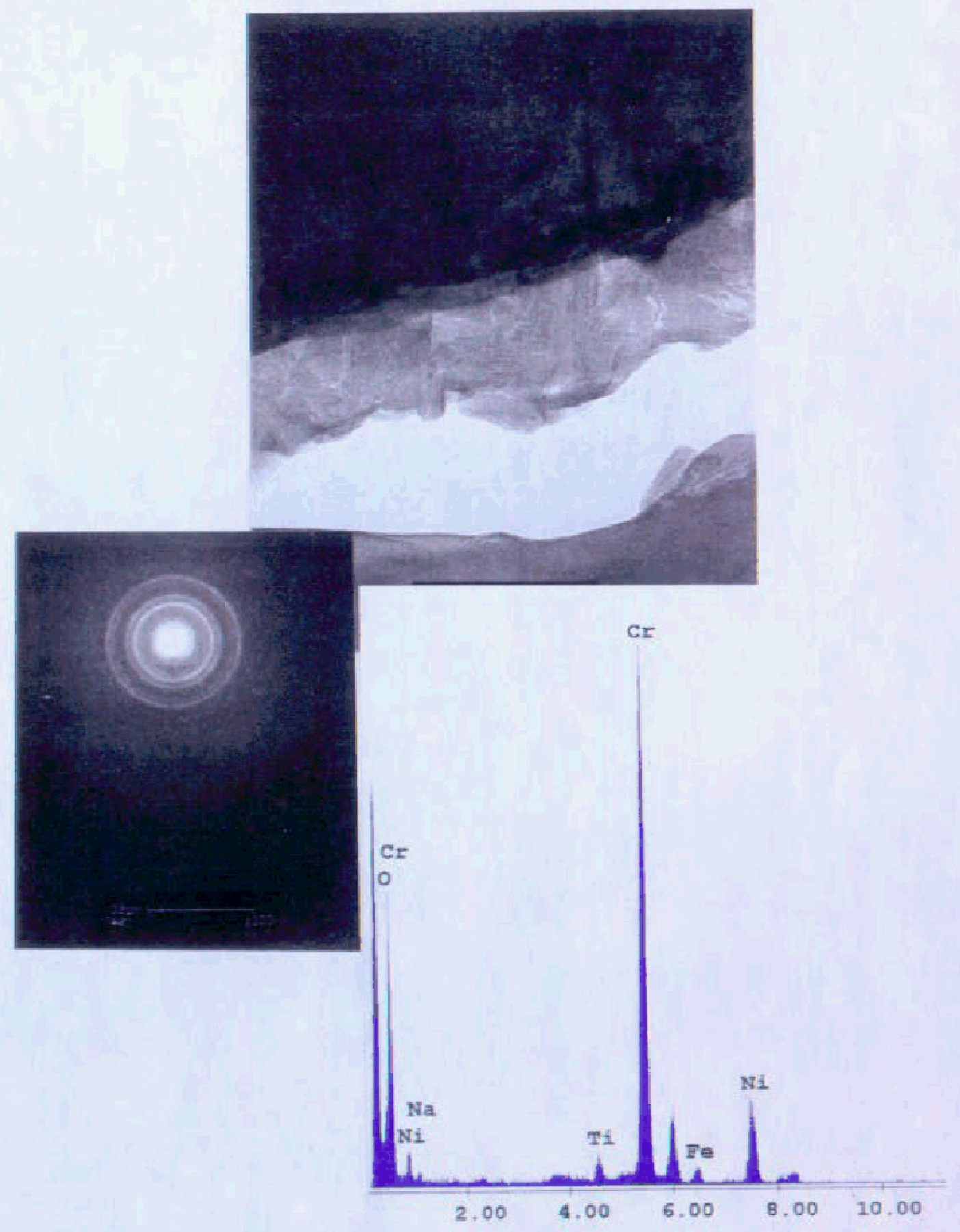

Figure 13. AEM bright field image showing cross-section of wide IGSCC crack away from carbides. Oxide corrosion product exhibits array of $\mathrm{Cr}$ rich crystallites with some $\mathrm{Ni}$, low $\mathrm{Ti}$ and trace Na. Diffraction pattern is consistent with spinel structure but the lines are diffuse (caustic, $307^{\circ} \mathrm{C}$, healed) 


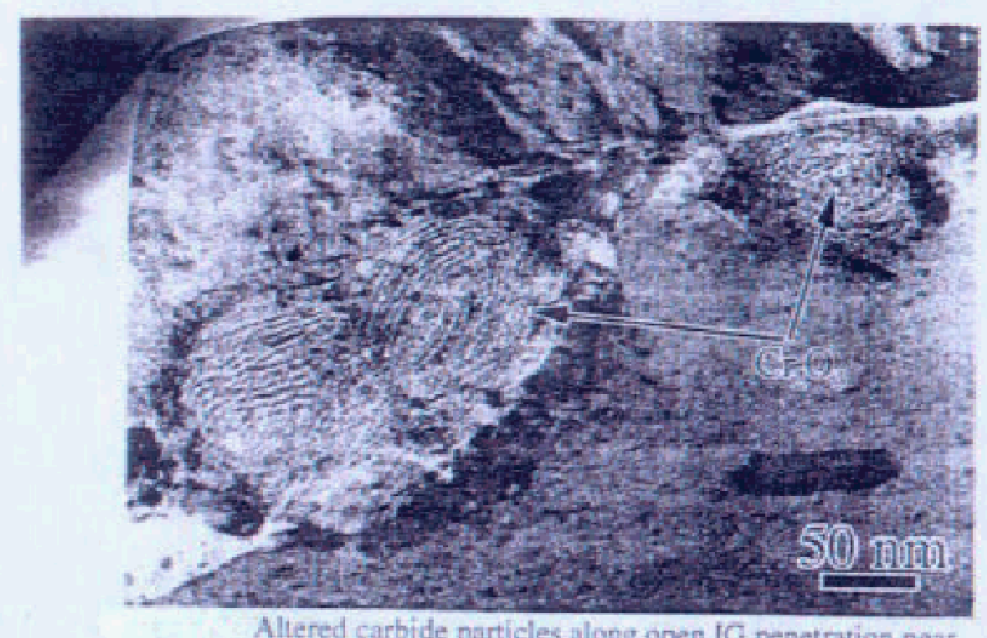
primary crack in OTSG nube.

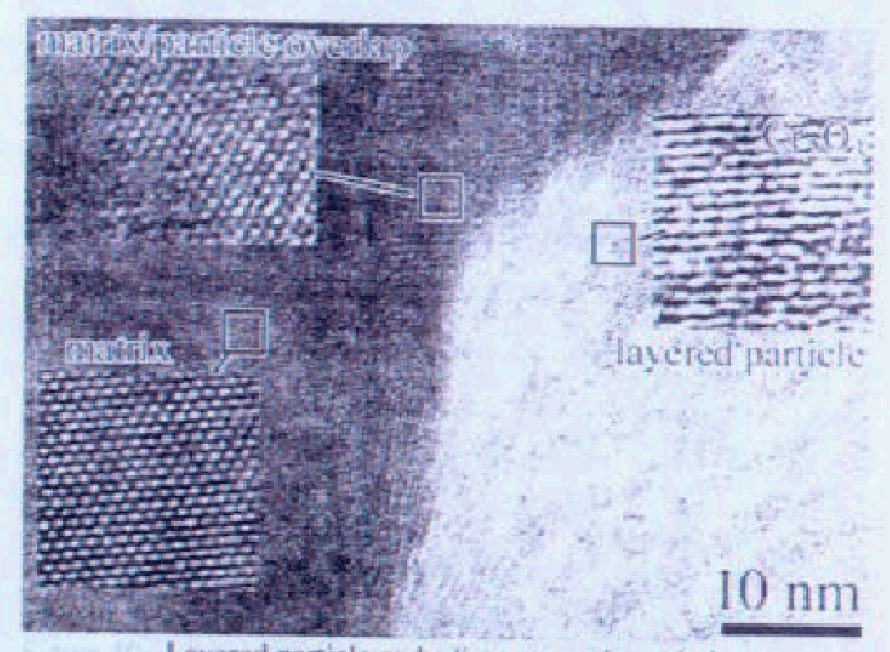

Laycred particle and adjacent metal matrix in

preoeding figure. Insets show crystall latrice images of selected areas.
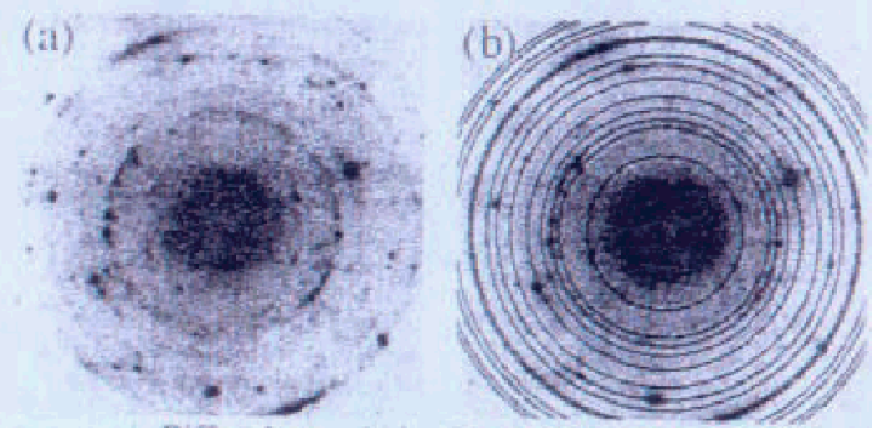

Difraction analysis of layered particle in Fig. 9. (a)

difraction pattem from particle area. (b) matching rings for $\mathrm{Cr}, \mathrm{O}$

Figure 14. AEM bright field image showing oxidized carbide from tubing from Oconee \#3 plant. Oxide reported as $\mathrm{Cr}$ rich polycrystalline $\mathrm{Cr}_{2} \mathrm{O}_{3}$ (Thomas and $\mathrm{Breummer}$, Reference 

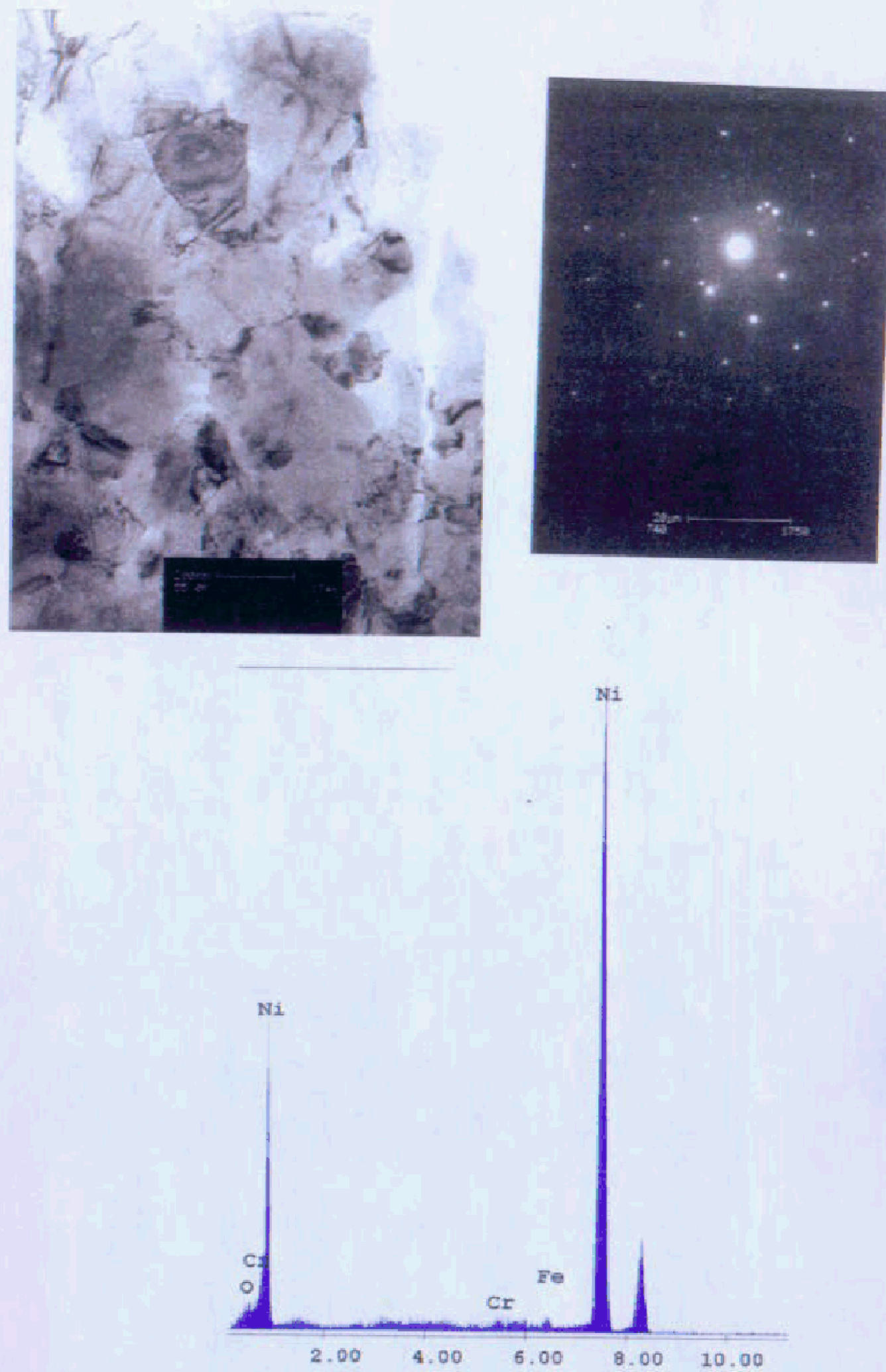

Figure 15. AEM bright field image showing planar section of bulk surface film consisting of
polycrystalline grains approing diffraction pattern indexes to $\mathrm{Ni}$. (caustic, $307^{\circ} \mathrm{C}$, healed) 

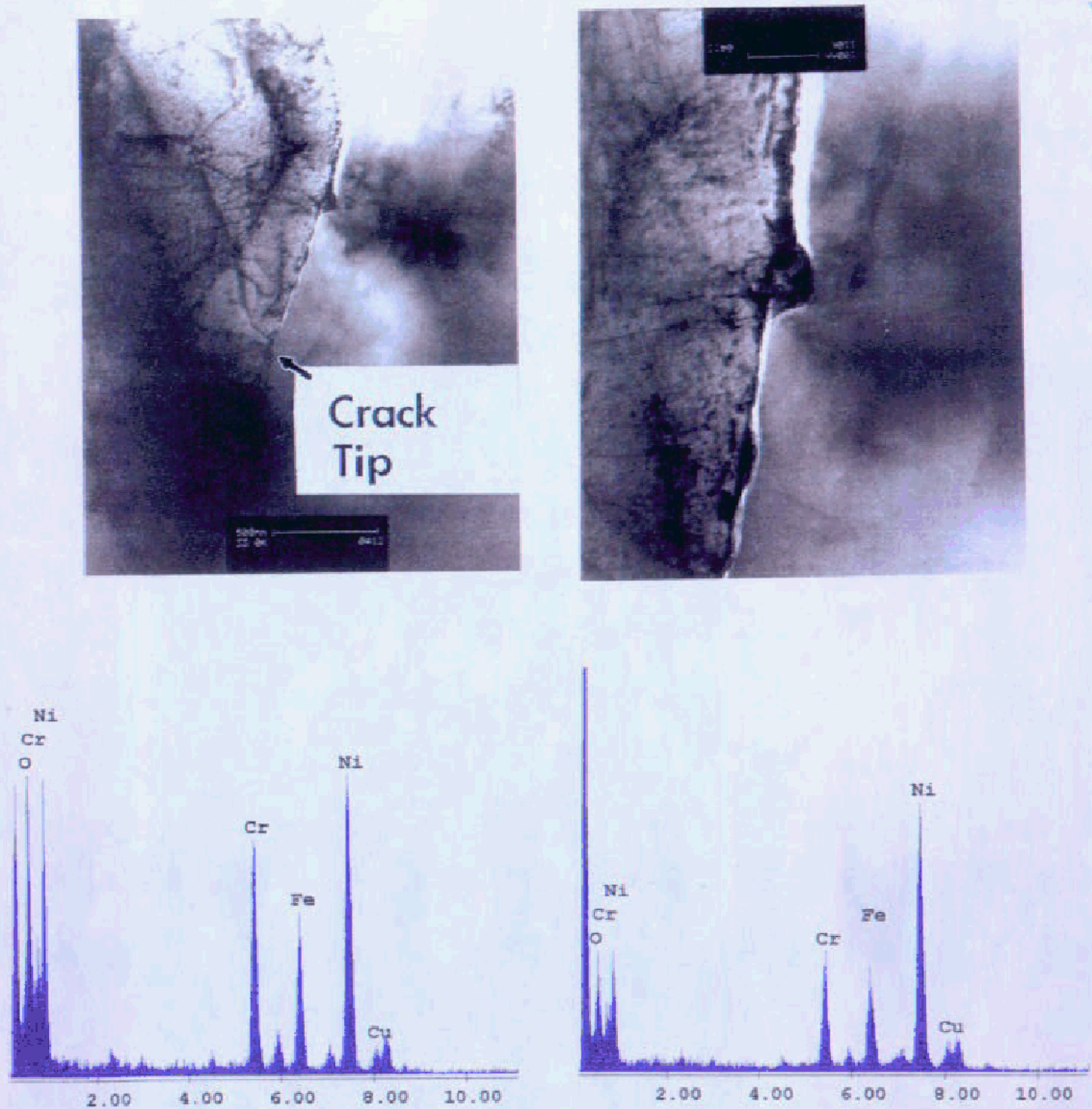

Figure 16. AEM bright field images showing IGSCC crack tip. Note sharpness of crack-tip. Xray spectrum from oxide in crack varies from $\mathrm{Ni}$ rich to $\mathrm{Ni}$ and $\mathrm{Cr}$ rich. (near-neutral hydrogenated water, $338^{\circ} \mathrm{C}, \mathrm{MA}^{980}$ ) 

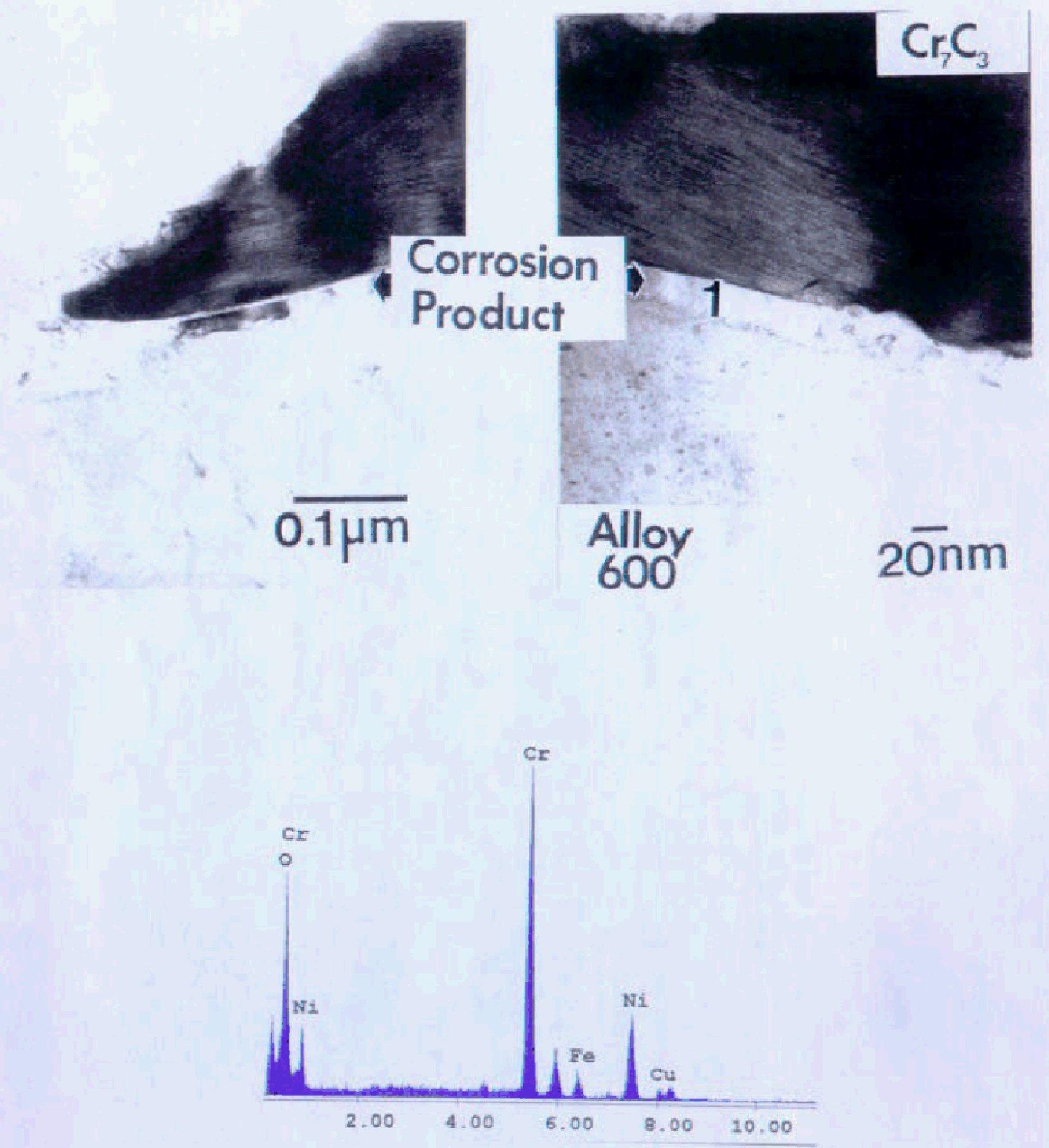

Figure 17. AEM bright field image showing $\mathrm{Cr}_{7} \mathrm{C}_{3}$ carbide along IGSCC crack. Top of image is main crack. Bottom of image is oxide layer between carbide and substrate. $\mathrm{X}$-ray spectrum from area 1 indicates a $\mathrm{Cr}$ rich oxide. (near- neutral hydrogenated water, $338^{\circ} \mathrm{C}, \mathrm{MA}^{980}$ ) 

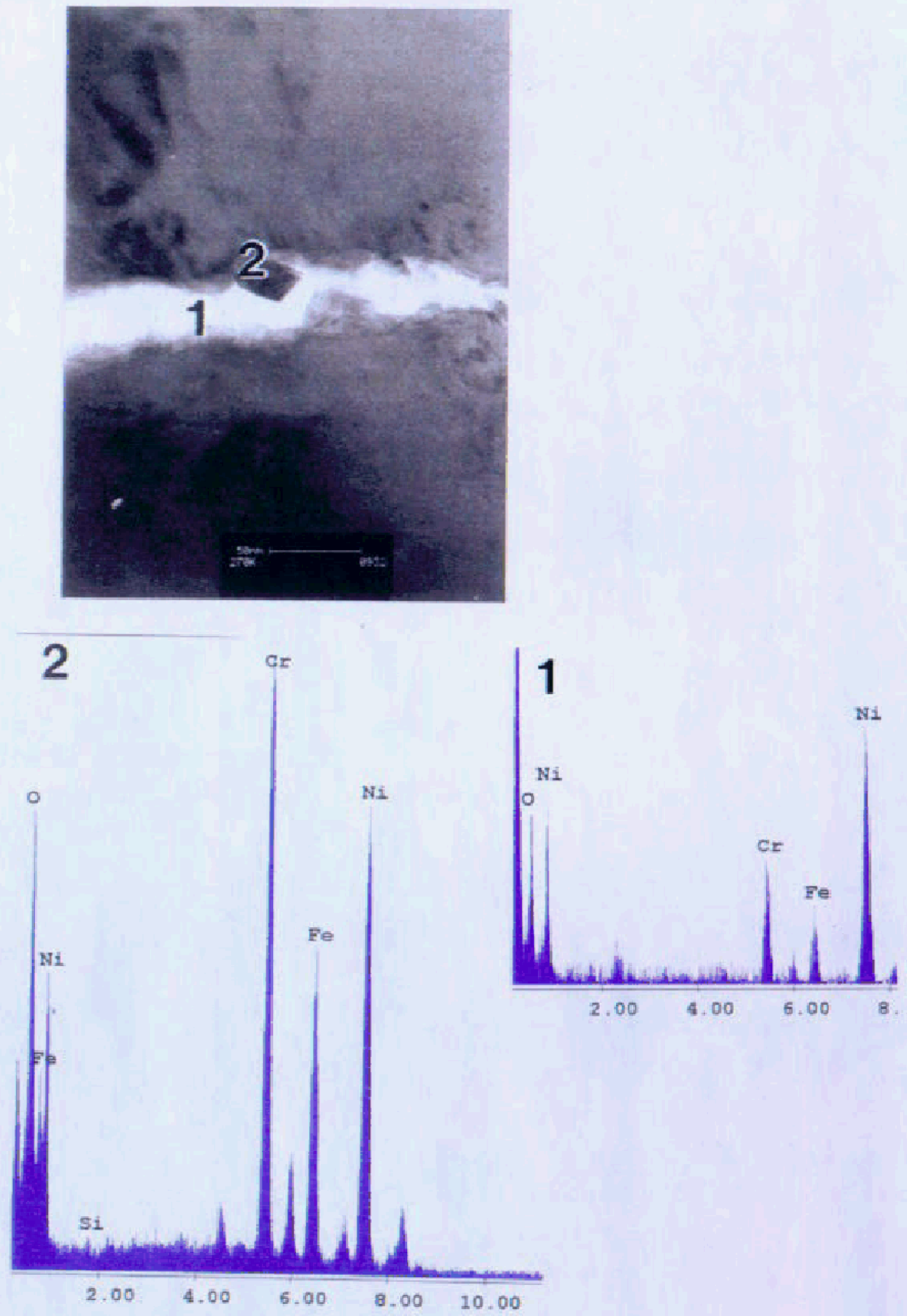

Figure 18. AEM high magnification image near IGSCC crack -tip showing very fine grain oxide area 1 and larger oxide crystal area 2. X-ray spectrum 1 and 2 from area 1 and 2 show Ni rich oxide with elemental ratios similar to the base metal and larger oxide with roughly equal $\mathrm{Fe}, \mathrm{Cr}$ and $\mathrm{Ni}$. (near- neutral hydrogenated water, $338^{\circ} \mathrm{C}, \mathrm{MA}^{98}$ ) 

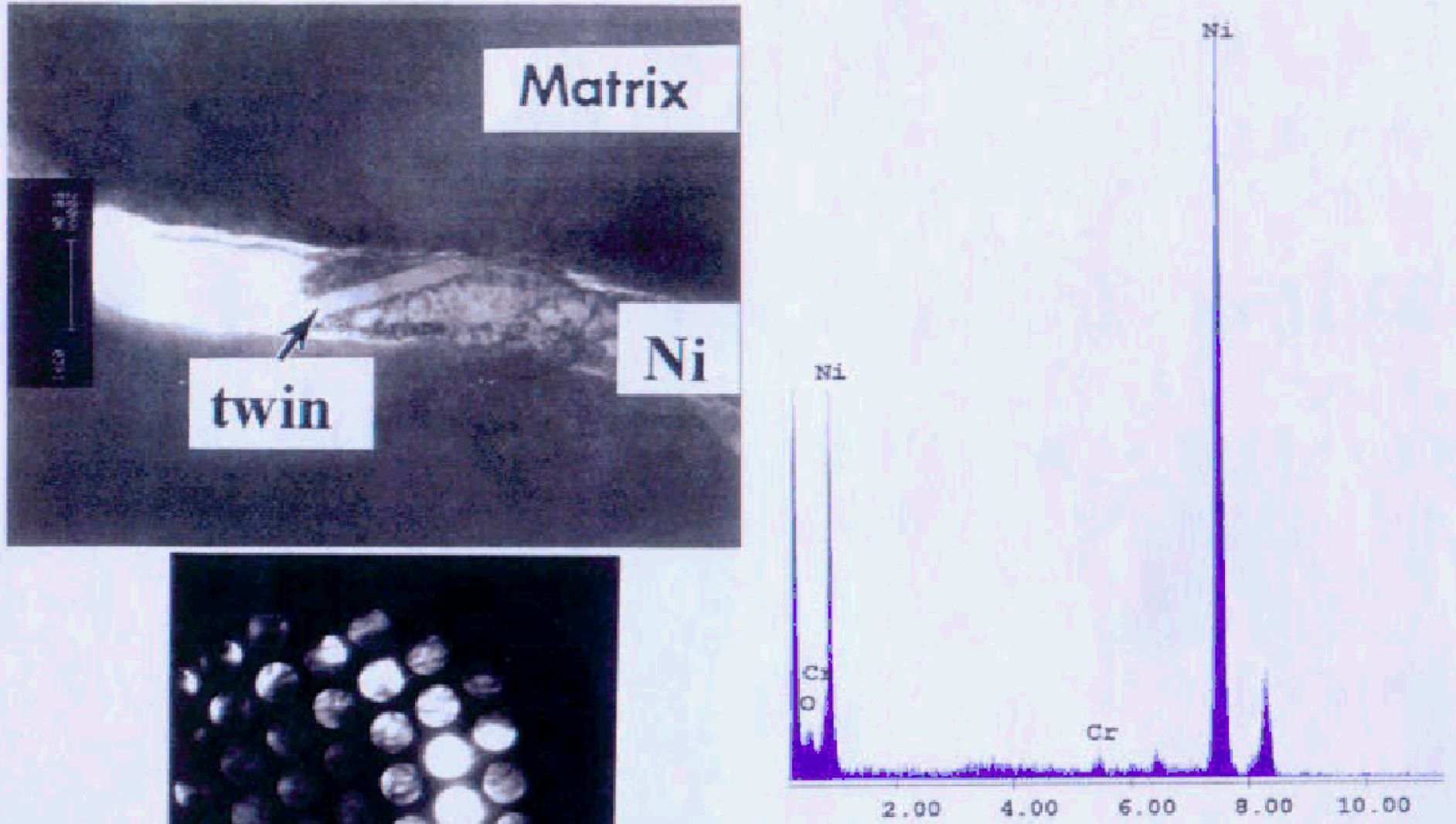

Figure 21. AEM bright field image showing cross-section of IGSCC crack. X-ray spectrum and electron diffraction pattern confirm that pure Ni metal is filling the crack. Note the twin within the $\mathrm{Ni}$ metal precipitate which does not match mating grains. (hydrogenated steam, $399^{\circ} \mathrm{C}$, 


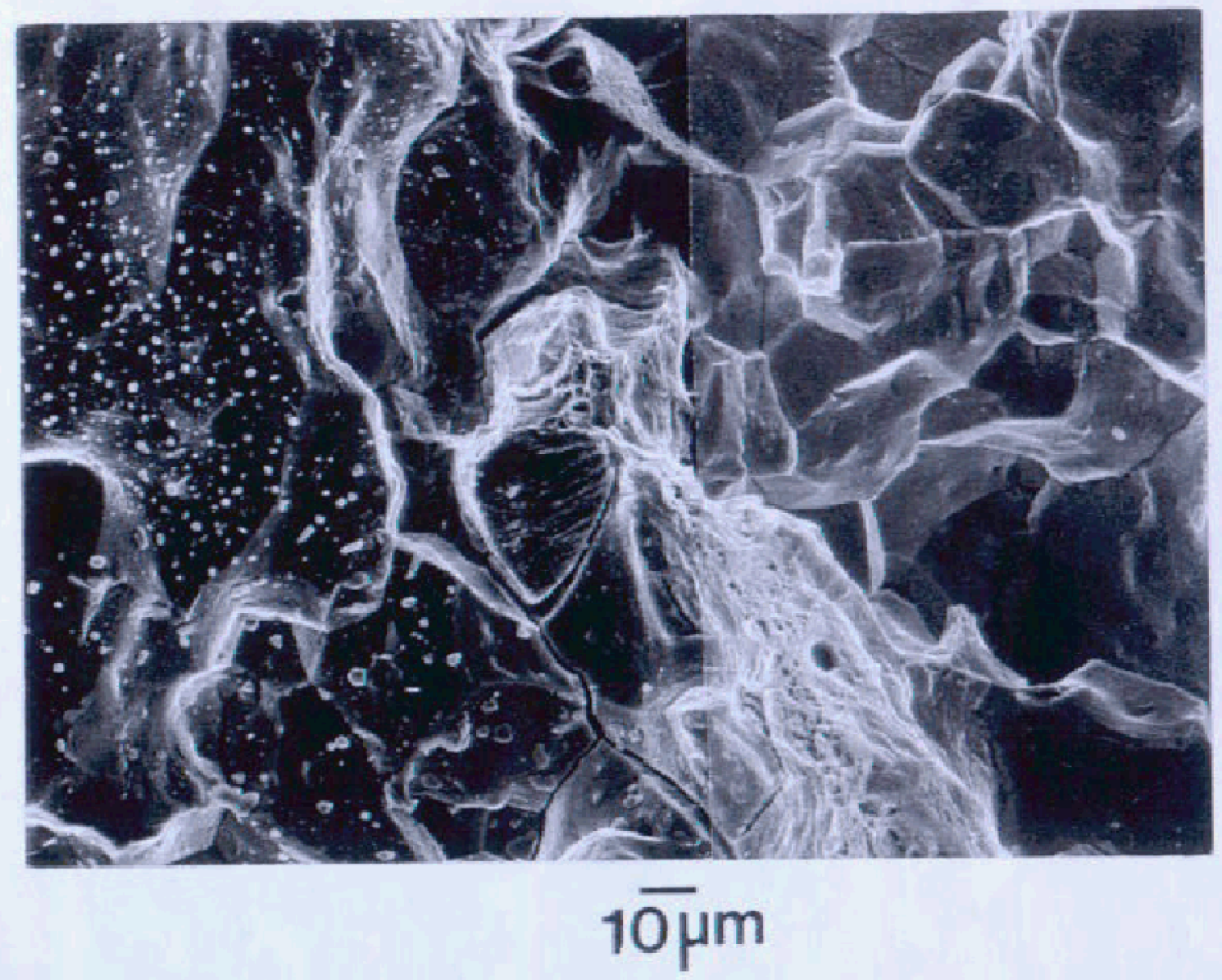

Figure 22. Secondary electron image showing IGSCC fracture surface near crack-tip. Note that $\mathrm{Ni}$ rich precipitates do not extend all the way to the crack-tip. (hydrogenated steam, $399^{\circ} \mathrm{C}$, $\mathrm{MA}^{1010}$ ) 


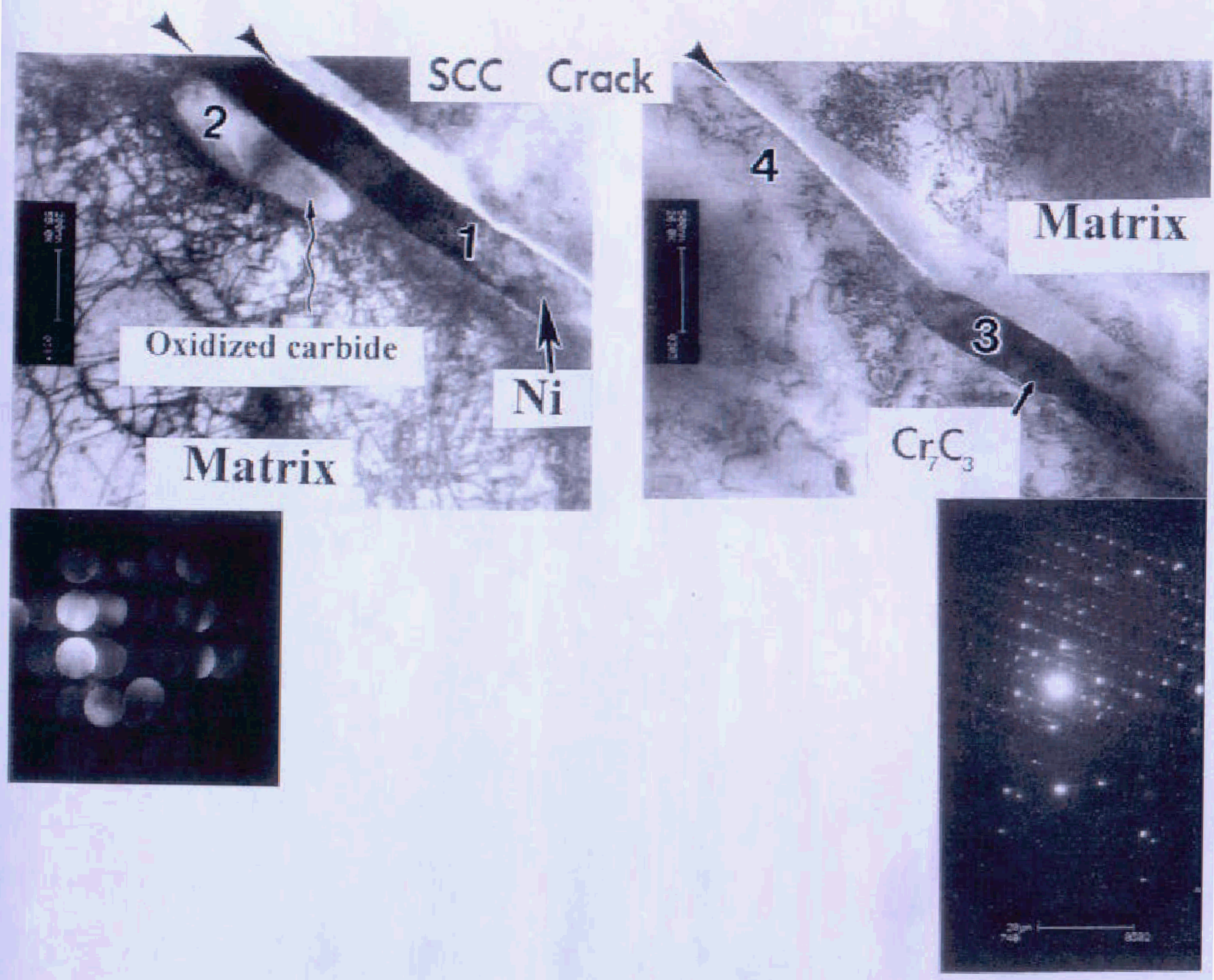

Figure 23 AEM bright field images and electron diffraction patterns showing IGSCC crack a) wider crack with $\mathrm{Ni}$ rich precipitate area 1 and single crystal oxide spinel area 2 . b) narrow crack near crack-tip intersecting unoxidized area 3 and adjacent to twin area 4 . Arrows denote crack width. (hydrogenated steam, $399^{\circ} \mathrm{C}, \mathrm{MA}^{1010}$ ) 


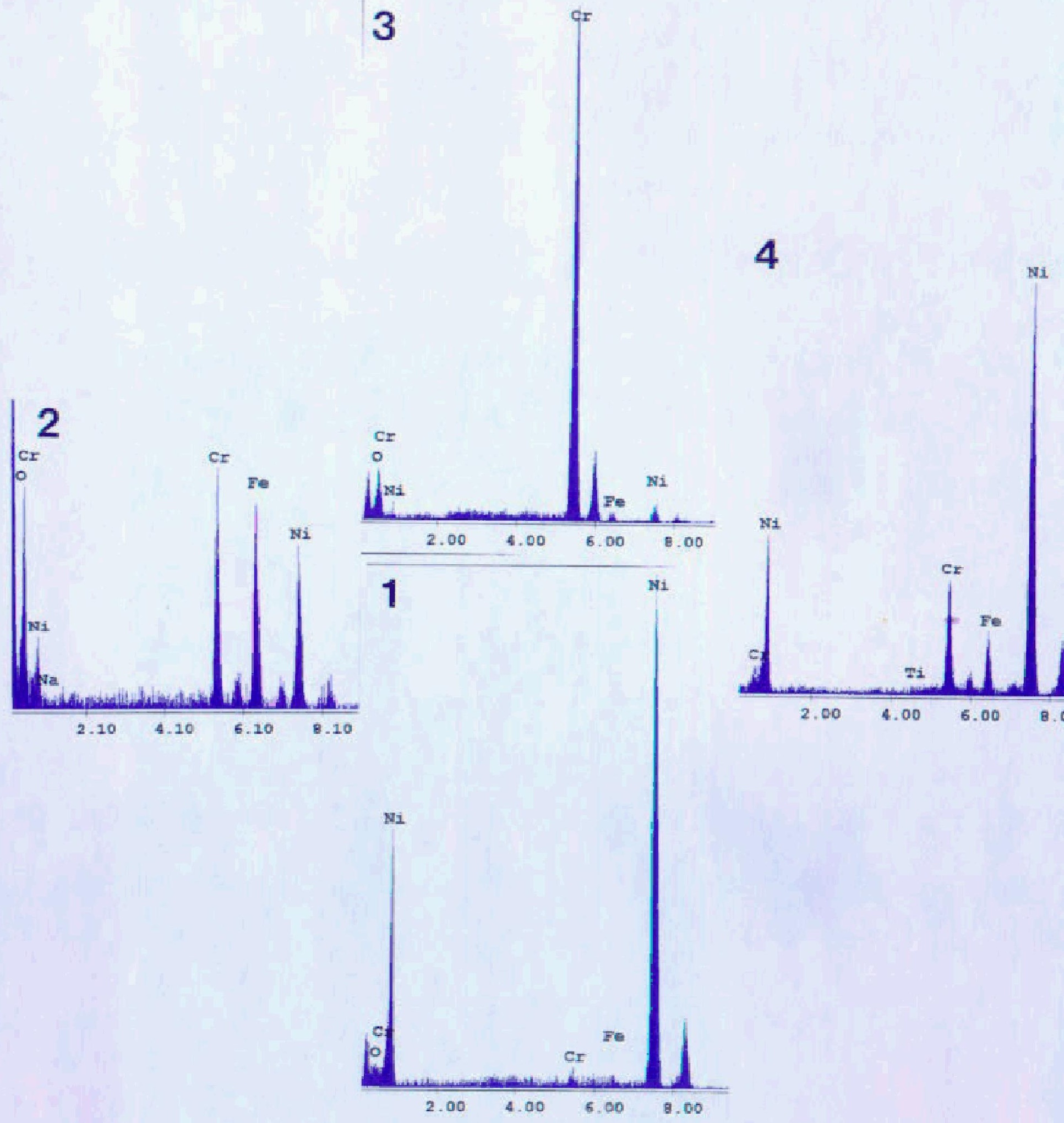

Figure 24. X-ray spectrum 1-4 from areas 1-4 in Figure 23. Area 1 is Ni metal, area 2 is single crystal oxide spinel, area 3 is $\mathrm{Cr}_{7} \mathrm{C}_{3}$ carbide and area 4 is alloy 600 matrix. (hydrogenated steam, $399^{\circ} \mathrm{C}, \mathrm{MA}^{1010}$ ) 

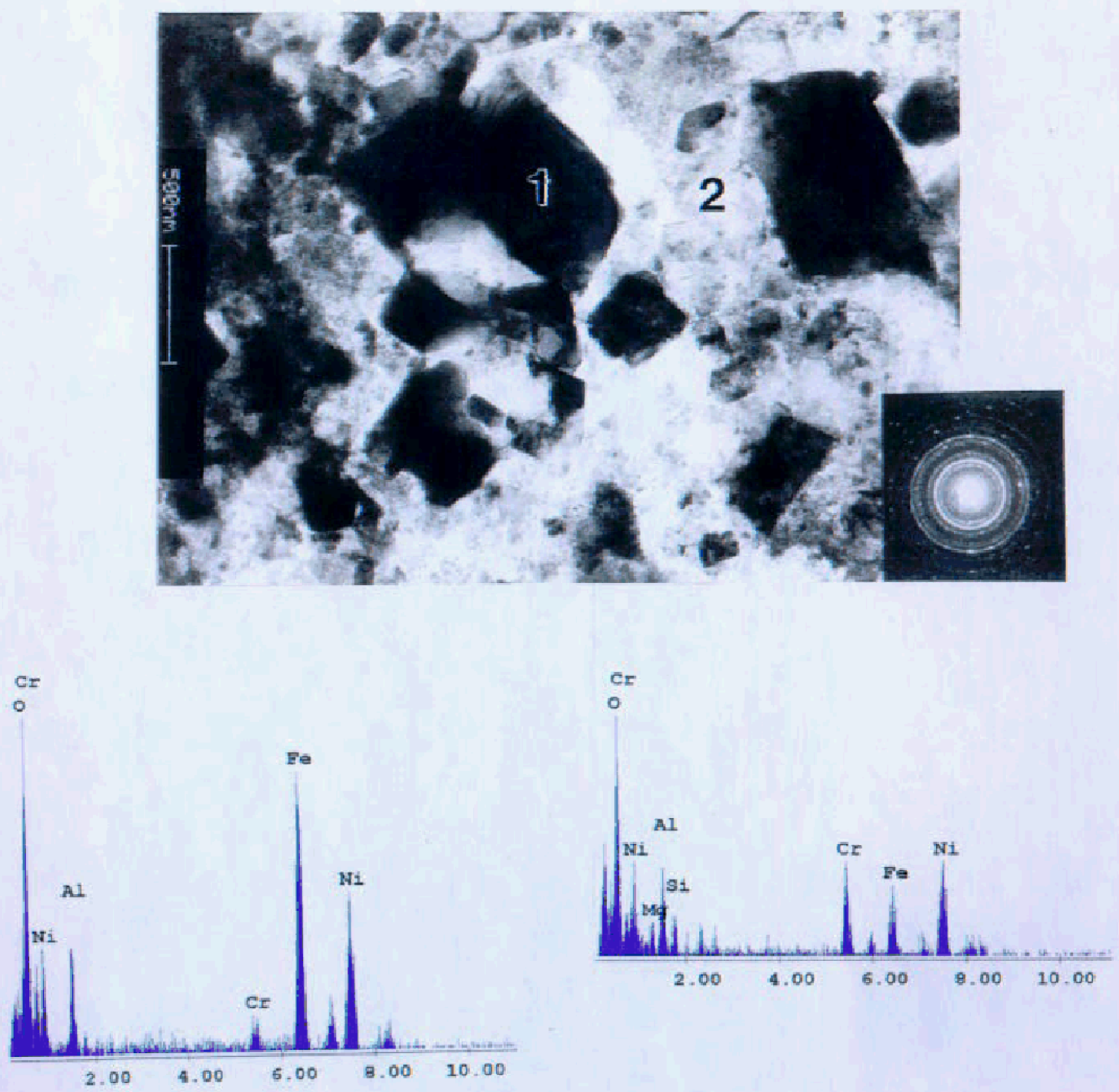

Figure 25. AEM bright field images showing plan view of bulk surface oxide. Electron diffraction pattern (inset) indexes to oxide spinel. $\mathrm{X}$-ray spectrum 1 and 2 from area 1 and 2 is $\mathrm{NiFe}_{2} \mathrm{O}_{4}$ and $\mathrm{Ni}_{5} \mathrm{Fe}_{(1-x)} \mathrm{Cr}_{2} \mathrm{O}_{4}$ respectively. (hydrogenated steam, $399^{\circ} \mathrm{C}, \mathrm{MA}^{1010}$ ) 